OPEN

SUBJECT AREAS:

POROUS MATERIALS

THERMOELECTRICS

ELECTRONIC DEVICES

BIOMATERIALS

Received

25 September 2013

Accepted

5 June 2014

Published

25 June 2014

\section{Correspondence and} requests for materials should be addressed to B.T. (tbrindan@iitk.ac. in) or M.D. (mainakd@ iitk.ac.in)

* These authors contributed equally to this work.

\title{
Electricity from the Silk Cocoon Membrane
}

\author{
Brindan Tulachan ${ }^{1 *}$, Sunil Kumar Meena ${ }^{2 *}$, Ratan Kumar Rai ${ }^{3}$, Chandrakant Mallick', \\ Tejas Sanjeev Kusurkar' ${ }^{1}$, Arun Kumar Teotia ${ }^{4}$, Niroj Kumar Sethy ${ }^{5}$, Kalpana Bhargava ${ }^{5}$, \\ Shantanu Bhattacharya ${ }^{6}$, Ashok Kumar ${ }^{4}$, Raj Kishore Sharma ${ }^{7}$, Neeraj Sinha $^{3}$, Sushil Kumar Singh ${ }^{8}$ \\ \& Mainak Das ${ }^{1,9}$
}

\begin{abstract}
'Bioelectricity, Green Energy, Physiology \& Sensor Group, Biological Sciences and Bioengineering, Indian Institute of Technology Kanpur, Kanpur, UP, 208016, India, ${ }^{2}$ Electrical Engineering, Indian Institute of Technology Kanpur, Kanpur, UP, 208016, India, ${ }^{3}$ Center for Biomedical Research, SGPGIMS Campus, Raebareli Road, Lucknow, UP, 226014, India, ${ }^{4}$ Department of Biological Sciences and Bioengineering \& Center for Environmental Sciences and Engineering, Indian Institute of Technology Kanpur, Kanpur, UP, 208016, India, ${ }^{5}$ Peptide and Proteomics Unit, Defense Institute Physiology and Allied Sciences, Defense Research Development Organization, Delhi, 110054 , India, ${ }^{6}$ Mechanical Engineering, Indian Institute of Technology Kanpur, Kanpur, UP, 208016, India ${ }^{7}$ Department of Chemistry, Delhi University, Delhi, 110007 , India, ${ }^{8}$ Functional Materials Group, Solid State Physics Laboratory, Defense Research Development Organization, Delhi, 110054 , India, ${ }^{9}$ Design Program, Indian Institute of Technology Kanpur, Kanpur, UP, 208016, India.
\end{abstract}

Silk cocoon membrane (SCM) is an insect engineered structure. We studied the electrical properties of mulberry (Bombyx mori) and non-mulberry (Tussar, Antheraea mylitta) SCM. When dry, SCM behaves like an insulator. On absorbing moisture, it generates electrical current, which is modulated by temperature. The current flowing across the SCM is possibly ionic and protonic in nature. We exploited the electrical properties of SCM to develop simple energy harvesting devices, which could operate low power electronic systems. Based on our findings, we propose that the temperature and humidity dependent electrical properties of the SCM could find applications in battery technology, bio-sensor, humidity sensor, steam engines and waste heat management.

ilk cocoon membrane (SCM) and spider silk are insect engineered biomaterials ${ }^{1-5}$. For centuries, both silkworm cocoon and spider silk has held a unique place in the textile and biomedical industry. Spider silk was used by the Greeks and Romans for wound dressing (IX-I B.C.). Surgical silk suture were used during last two centuries (XIX-XX A.D.). During the last century, silk has found applications in cell culture and tissue engineering (XX-XXI A.D. $)^{4-7}$. Apart from silk cocoon's use in extracting silk fiber, this complex fibrous protein membranous shell acts as a protective enclosure ensuring successful metamorphosis of the silkworm pupae to silk $\mathrm{moth}^{8-10}$. It offers the dormant pupae protection against the predators ${ }^{11-19}$. It is further equipped with features like carbondioxide gating ${ }^{20}$, free flow of oxygen ${ }^{21}$, fluorescent coating ${ }^{22}$, photo-protection ${ }^{23}$, temperature regulation $^{20,24-27}$, UV protection ${ }^{28}$, water-proofing ${ }^{29}$ which may be vital for the growth, development and survival of the developing pupae. Further SCM could be transformed into graphene nano-structure, upon pyrolysing it in an inert environment ${ }^{30}$. In essence, SCM has versatile functional features.

Till date more than 4000 different species of silk moth has been documented in the literature. Only very few of them has been domesticated and commercially exploited for silk production. The rest of the species, which are yet to be domesticated, are considered as wild silk. One major domesticated species, which has been commercially exploited for a long time is mulberry silk (Bombyx mori). The name mulberry silk owes to the fact that these silk worms feed on mulberry trees. On the contrary, the wild silkworms feed on wide range of trees, which eventually influences the physico-chemical properties of their silk fibers ${ }^{1-19,31}$.

Geographically, ninety percent of the global commercial silk production is concentrated in the tropical and sub-tropical regions of China and India ${ }^{1-20,31}$, which experience wide diurnal and seasonal variation of temperature and relative humidity (RH). Apart from it, large number of wild silk species grows in the tropical and subtropical regions of African continent ${ }^{11,15,16,19}$. Several wild silk cocoon species as well as spider silk have higher elemental contents $(\mathrm{Na}, \mathrm{K}, \mathrm{Cl}, \mathrm{Mg}, \mathrm{S}, \mathrm{Cu}, \mathrm{Ca}, \mathrm{P}, \mathrm{Zn})^{20,32-37}$. Copper has been shown to involve in silk formation process of Bombyx mori ${ }^{33-35}$. It has been suggested that $\mathrm{Na}, \mathrm{Cl}$ and $\mathrm{K}$ ions play a role in spider silk formation ${ }^{36,37}$. Some of the wild silk cocoon species have a calcium oxalate crystals on their outer surfaces ${ }^{20,31,38-42}$. Our previous 
study has suggested that calcium oxalate possibly play a role in gas diffusion across Antheraea mylitta silk cocoon membrane ${ }^{20}$.

Since the developing pupae (inside the cocoon) grow in the tropical and sub-tropical belts, it has to withstand a wide diurnal and seasonal variation of temperature and relative humidity $(\mathrm{RH})$. Long back entomologists anticipated that SCM may have certain thermoregulatory features ${ }^{20,24-27}$. The systematic study of the phenomenon of thermoregulation in insect nest was initiated in the beginning of the $19^{\text {th }}$ century $^{43-51}$. As far back as 1971 , while studying the phenomenon of thermoregulation in the nest of social insects (Hornet, Vespa orientalis), late Jacob S Ishay of Tel Aviv University, observed that 'silk cap of the hornet nest' (which forms the top cover of the nest; see Figure S1) possesses certain thermo-physical properties ${ }^{52}$. His subsequent studies during 1990s and early 2000, have revealed that 'silk cap of hornet' posses certain thermoelectric properties which may play a key role in regulating the temperature of the Hornet's nest ${ }^{24,25,53-55}$. One of our previous work with Antheraea mylitta cocoon, showed that, this membrane also posses certain thermo-regulatory features ${ }^{20}$. The present work has its genesis from our previous work ${ }^{20}$ and the findings of Jacob S Ishay ${ }^{24,25,52-55}$.

Ishay's works documented the flow of current across the 'silk cap membrane' of hornet nest ${ }^{24,25,53-55}$. But he could not clearly pinpoint the origin of the charge moieties, which resulted in current flow. He proposed that the silk fiber with its inner core of fibroin and outer gummy layer of sericin is functioning like $n$ and $p$ type semiconductor material ${ }^{24,25}$. His mineral analysis data highlighted the presence of common elements like $\mathrm{Mg}, \mathrm{P}, \mathrm{S}, \mathrm{Cl}, \mathrm{K}$ and $\mathrm{Ca}$ in the silk cap of Hornet, and he assumed that these minerals are acting as natural dopants in silk-semiconductor material. These seminal works of Ishay, on exploring the thermo-electrical properties of 'silk cap of hornet nest' remained in literary isolation for last three decades, since no other scientific group persuaded or followed up on these lines of work. Further, it has not been explored whether such 'thermo-electrical properties are inherent in other silk fiber proteins' or it is solely a unique feature of 'silk cap of hornet nest'. Our exploration in this direction is to answer some of these fundamental questions related to thermo-electrical properties of silk.

In this study, we selected more easily available, commercial silk cocoon samples available in india (Figure S2), a mulberry silk i.e Bombyx mori and a non-mulberry silk i.e Antheraea mylitta. In this work, our major goal was to study the electrical properties of these silk cocoon membranes. Hence we asked the following questions:

1. Could the silk cocoon membranes of Bombyx mori and Antheraea mylitta generate electricity, as documented by Ishay in his work on silk cap membrane covering the hornet's nest (Vespa orientalis).

2. If these silk cocoon membranes have the inherent ability to generate electricity, could we harness this electricity for some useful work?

We initiated our investigation with the following working hypothesis: 'when water molecules get trapped in the fibrous matrix of SCM, it interacts with the naturally occurring ion forming elements, and generate certain ionic mobile charge carriers. These charge carriers trigger flow of electricity across SCM, which could be modulated by temperature'.

\section{Results}

Morphology of Bombyx mori and Antheraea mylitta silk cocoons. Representative pictures of Bombyx mori and Antheraea mylitta silk cocoons are shown in Figure 1. Visual observations indicate that, the outer surface of the cocoons of Bombyx mori species is comparatively smoother, as compared to the outer surface of the cocoons of Antheraea mylitta species. The outer surface of Antheraea mylitta cocoon has a coarse texture. Several wild species of cocoon have such coarse outer surface $\mathrm{e}^{20,38-42}$.

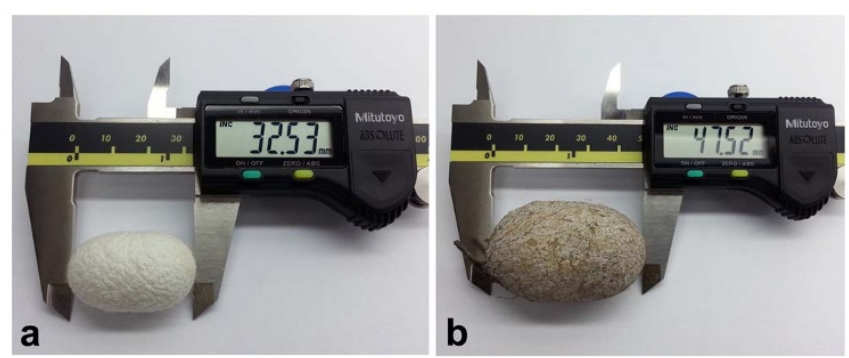

Figure $1 \mid$ Representative picture and average size of Bombyx mori and Antheraea mylitta cocoons (a) Digital caliper showing the size of Bombyx mori cocoon and has a soft texture (b) Antheraea mylitta silk cocoon has coarse texture and is larger than the Bombyx mori.

Comparative scanning electron microscopic (SEM) studies of SCM. We perform SEM analysis of the Bombyx mori and Antheraea mylitta SCM (Figure 2). The SEM images of the outer and inner surfaces of silk cocoon indicate the woven fibrous matrix of SCM. The outer surface of Antheraea mylitta exhibits rough morphology and the inner surface shows smooth morphology as reported in earlier studies ${ }^{20}$. As reported earlier ${ }^{20}$, Calcium oxalates crystals (approximately 1 micron) can be distinctively visible in the outer surface of the Antheraea mylitta cocoon. Earlier it has been documented that several wild species of cocoons carry calcium oxalate crystals, which is partly responsible for the coarse outer texture of these cocoons $\mathrm{s}^{20,38-42}$. Calcium oxalate crystals are not present in the Bombyx mori cocoon surface. The silk fiber threads of the Antheraea mylitta are slightly thick ( $\sim 20$ microns) as compared to the Bombyx mori ( $\sim 10$ micron), as seen from the SEM images. The pores are more visible in the Bombyx mori structure as compared to the Antheraea mylitta membrane. Inner surface of both the cocoons are smoother than the outer surface.

Comparative energy dispersive $\mathrm{X}$-ray spectroscopy (EDAX) analysis of SCM. EDAX analysis of the Bombyx and Antheraea silk cocoon was done to address the elemental composition of the membranes (Figure 3). Apart from carbon $(\mathrm{C})$, nitrogen $(\mathrm{N})$ and oxygen $(\mathrm{O})$, in both the cocoon species trace amounts of sodium $(\mathrm{Na})$, chloride $(\mathrm{Cl})$, potassium $(\mathrm{K})$, magnesium $(\mathrm{Mg})$ and sulfur $(\mathrm{S})$ could be detected. Calcium $(\mathrm{Ca})$ is found in significant concentrations in Antheraea silk cocoon, whereas it is found in trace amounts in Bombyx. High concentration of calcium in Antheraea is understandable, since several wild cocoon species have high concentrations of calcium oxalate crystals ${ }^{20,38-42}$. Trace amount of $\mathrm{Zn}$ and $\mathrm{P}$ can be detected in Antheraea mylitta. Previous studies on Antheraea, has indicated the presence of $\mathrm{Zn}$ and $\mathrm{P}^{20}$. The presence of $\mathrm{Cu}$ was detected in the Bombyx mori cocoon. Earlier studies on Bombyx mori have indicated the presence of copper in the structure ${ }^{33-35}$.

Comparative porosity analysis of SCM. Next, we went ahead and made a comparative porosity analysis of the Antheraea and Bombyx SCM (Table 1). The detail of the porosity analysis is described in methods section ${ }^{56}$. The porosity values for Bombyx are in close agreement with a recently reported study ${ }^{29}$. The Bombyx membrane is significantly more porous than the Antheraea. Upon demineralization of these SCM, we did not observe any significant change in porosity. Demineralization was done by a previously described method of ethylenediaminetetraacetic acid (EDTA) treatment of $\mathrm{SCM}^{32}$. (Refer to methods section for details on demineralization process and conductivity measurement section in supplementary information (S3, S4 and S5) to verify the extent of demineralization. 


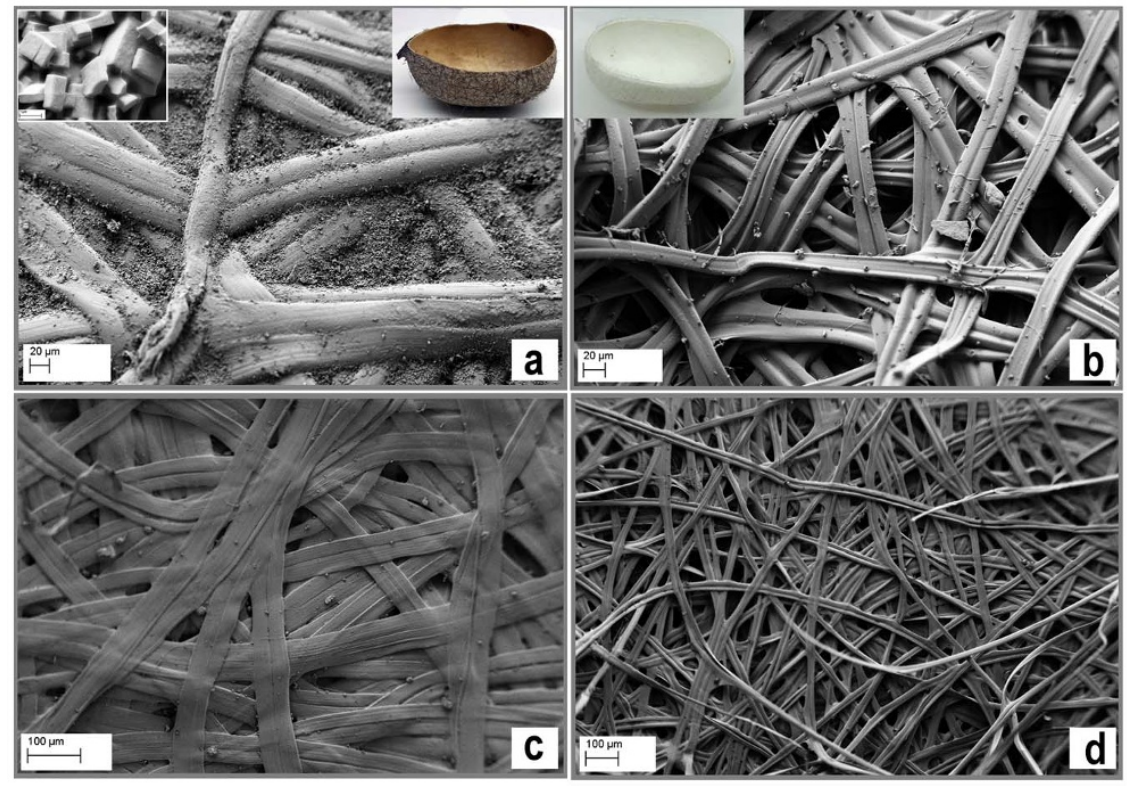

Figure 2 Scanning electron microscopy of the SCM (a) Rough outer surface of Antheraea mylitta with inset showing the crystals of calcium oxalate (Scale Bar 1 micron) and another inset displays half-cut cocoon. (b) Smooth outer surface of the Bombyx mori cocoon as compared to Antheraea mylitta, with inset of the half-cut cocoon. (c), (d) Smooth inner surfaces of both the types display the porous, fibrous matrix of the SCM.

Developing a system to study the electrical properties of SCM. In order to do the comparative study of the electrical properties of the two SCM, a standard device was assembled as shown in Figure 4. The detail of the device is in the methods section. The dimension of the devices developed from Bombyx mori and Antheraea mylitta SCM was kept identical, except the inherent difference in thickness between the Bombyx mori and Antheraea mylitta SCM. We used two different electrodes aluminum and copper. The SCM was sandwiched between the two electrodes. The electrodes solely make physical contact with the SCM. We did not use any binder (like silver paste) to attach the electrodes onto the cocoon surface. This is done, in order to ensure that that we are not adding any contaminating chemicals in the measuring system.

Comparative electrical properties of SCM. The current and voltage across SCM was measured using the device shown in figure 4 . These electrical parameters were recorded under five different conditions: dry cocoon, moist cocoon, water vapor exposed cocoon, demineralized cocoon exposed to water vapor and $\mathrm{NaCl}$ doped cocoon exposed to water vapor (Figure 5, Table 2). Among all the conditions, we obtained negligible current value in dry SCM. When SCM is allowed to absorb moisture, and the current recordings were made in the room temperature $\left(30^{\circ} \mathrm{C}\right)$, we observed an acute increase in current value. We observed a further increase in current value, when the moistureladen cocoon is exposed to the stream of water vapor (Table 2). The current value is further enhanced, when SCM was doped with common salt solution ( $1 \mathrm{M} \mathrm{NaCl}$ solution) and the membrane is exposed to the stream of water vapor. A similar trend was followed by both Bombyx mori and Antheraea mylitta SCM. The current value decreased when the cocoon sample was demineralized and exposed to water vapor. Overall we obtained higher current density in Antheraea mylitta cocoon and this may be explained by the fact that it has higher mineral contents. In case of voltage readings, we obtained lowest value from dry SCM and highest value was recorded from water vapor exposed SCM (Table 2). In this case too, both types of SCM followed a similar trend.
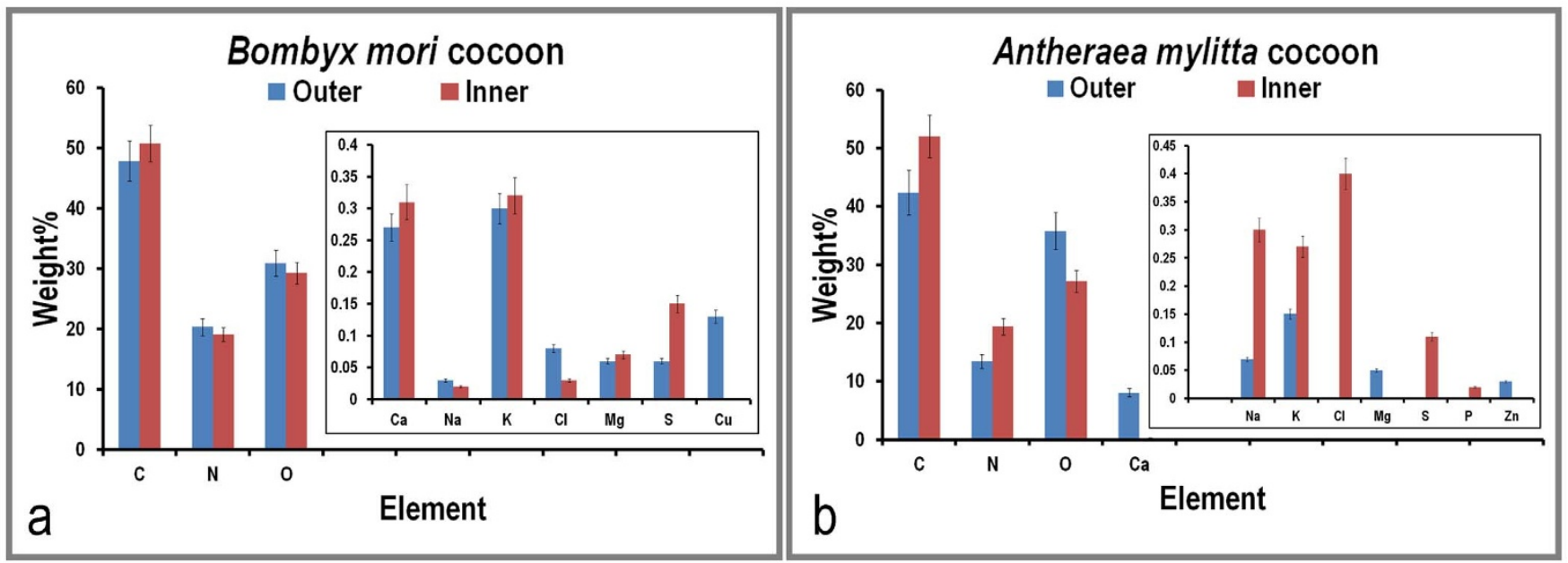

Figure 3 Energy dispersive X-ray spectroscopy (EDAX/EDS) analysis of the SCM showing the presence of elements like sodium, potassium, chloride, magnesium and sulfur in SCM (a) EDS data for Bombyx mori (b) EDS data for Antheraea mylitta. 
Table 1 | A Comparative porosity analysis for Bombyx and Anthreraea SCM using fluid uptake method. Two different liquids were used to quantify the porosity of the two different SCM

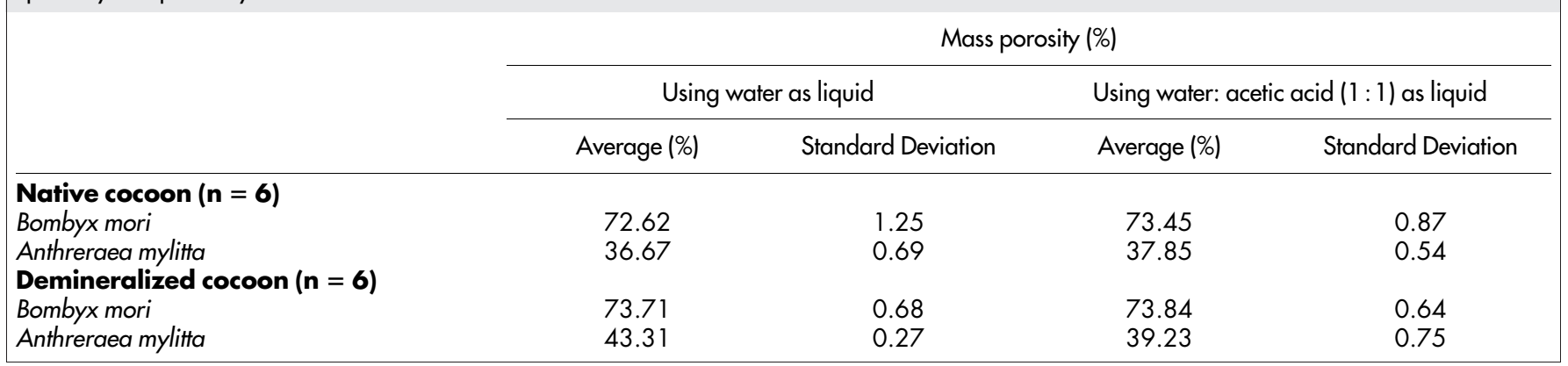

Temperature and humidity dependent current and voltage profile of SCM. Silk cocoon acts as a thermo-regulatory membrane, which helps in maintaining an ambient temperature inside the cocoon ${ }^{2024-27}$. When the surface of SCM is exposed to varying temperature, in the presence of humidity, we observed a change in current density across membrane (Figure 6). The magnitude of the current increased with temperature. This shows that current across SCM depends on humidity and temperature of the surrounding environment. Whereas the voltage recorded was almost constant in temperature range of $10-40^{\circ} \mathrm{C}$ and exhibit a sharp rise at temperatures above $40^{\circ} \mathrm{C}$. Interestingly both the current and voltage showed a sharp spike around $50^{\circ}-60^{\circ} \mathrm{C}$. This sharp peak is observed for both the cocoon types.

Current-voltage (I-V) characteristics of SCM. The I-V studies were done using Vander Pauw technique, which revealed that the temperature modulates the resistivity of the material, thereby regulating the current flux across SCM (Figure 7). Studies were conducted at $80^{\circ} \mathrm{C}$, in the presence of water vapor and the same SCM was used for the recordings at $30^{\circ} \mathrm{C}$ after an interval of 10 minutes. This study showed that the temperature and moisture regulates the resistivity of the material. Pattern of the I-V curves were similar in both the SCM, but values were slightly higher in Antheraea mylitta. However, no response was observed when I-V studies were conducted in the absence of humidity. This is due to a very high resistance of SCM, thus behaving more like an insulator, in a dry condition. A similar humidity-dependent boost in current has been previously reported for other natural biomaterials like the silk cap of hornet nest and cuticle of the oriental hornet ${ }^{24,25,53,54}$.

Determining the possible origin of charge carriers in SCM. After investigating the humidity and temperature dependent electrical properties of SCM, we investigated the possible origin of the charge carriers within SCM and the type of electrical conduction, which might be responsible for triggering current flux. In our previous experiments, we observed that, when the SCM was doped with common salt solution ( $1 \mathrm{M} \mathrm{NaCl}$ solution), it resulted in maximum current flux (Figure 5, Table 2). Further, in the absence of humidity, no significant current was measured across fibrous protein matrix of SCM. These observations, slims down the chances of electronic conduction, instead raised the possibility of some form of ionic conduction across the membrane. One of the possibilities could have been that, when SCM is exposed to moisture and water vapor, the water molecules diffuses into its porous matrix, becomes mobile, and interact with the common ion forming elements like $\mathrm{Na}, \mathrm{K}, \mathrm{Cl}$ as well as with the protein matrix and resulting in the generation of charged ionic species, that might generate electricity. The mobility of the water molecules could be further modulated by temperature. To test this reasoning, we first performed some simple experiments of measuring the conductivity of the water passing through the SCM (Figure S3, S4, S5 Supplementary information). We filled the cocoons with deionized water (conductivity $=1.57 \mu \mathrm{S}$ ) and measured the conductivity and total dissolved solid (TDS) of the water passing through SCM and
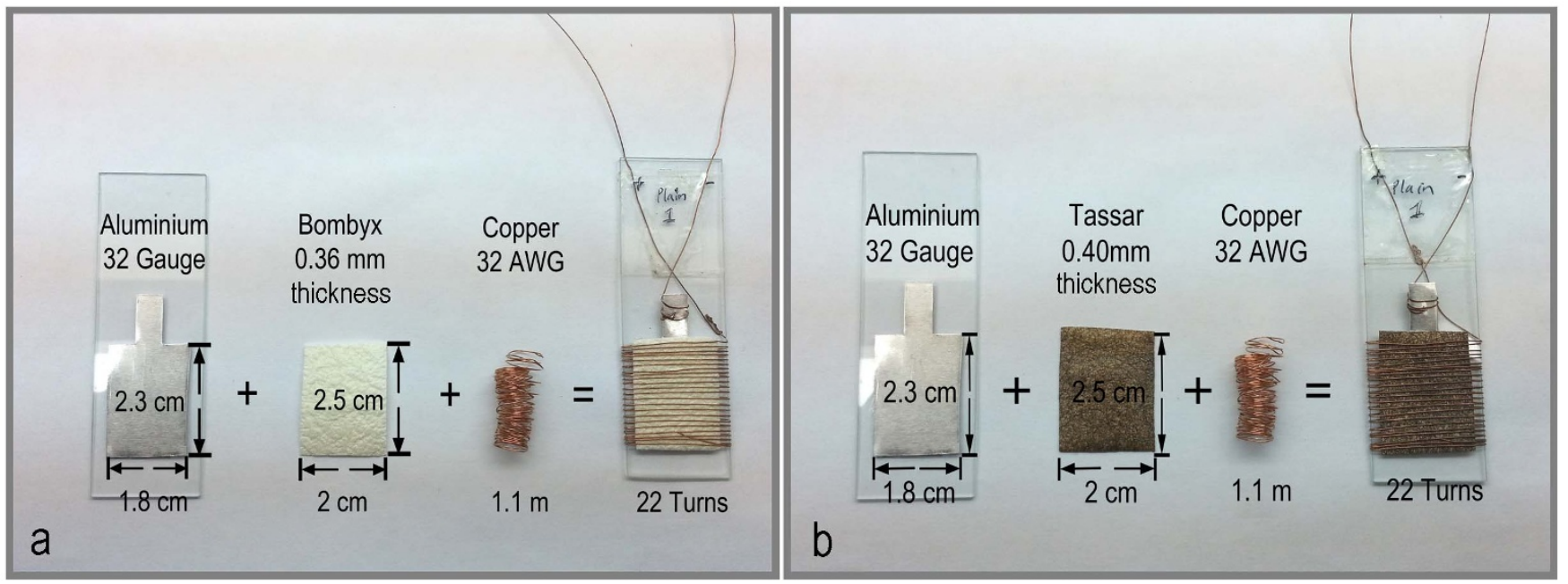

Figure $4 \mid$ Simple device prepared by physically connecting the two electrodes to the SCM surface. This standard device is used all throughout the study to perform the electrical measurements of different SCM. This uniform device helps in comparing the data obtained from 2 different SCMs (a) Device prepared with Bombyx mori SCM (b) Device prepared with Antheraea mylitta SCM. 


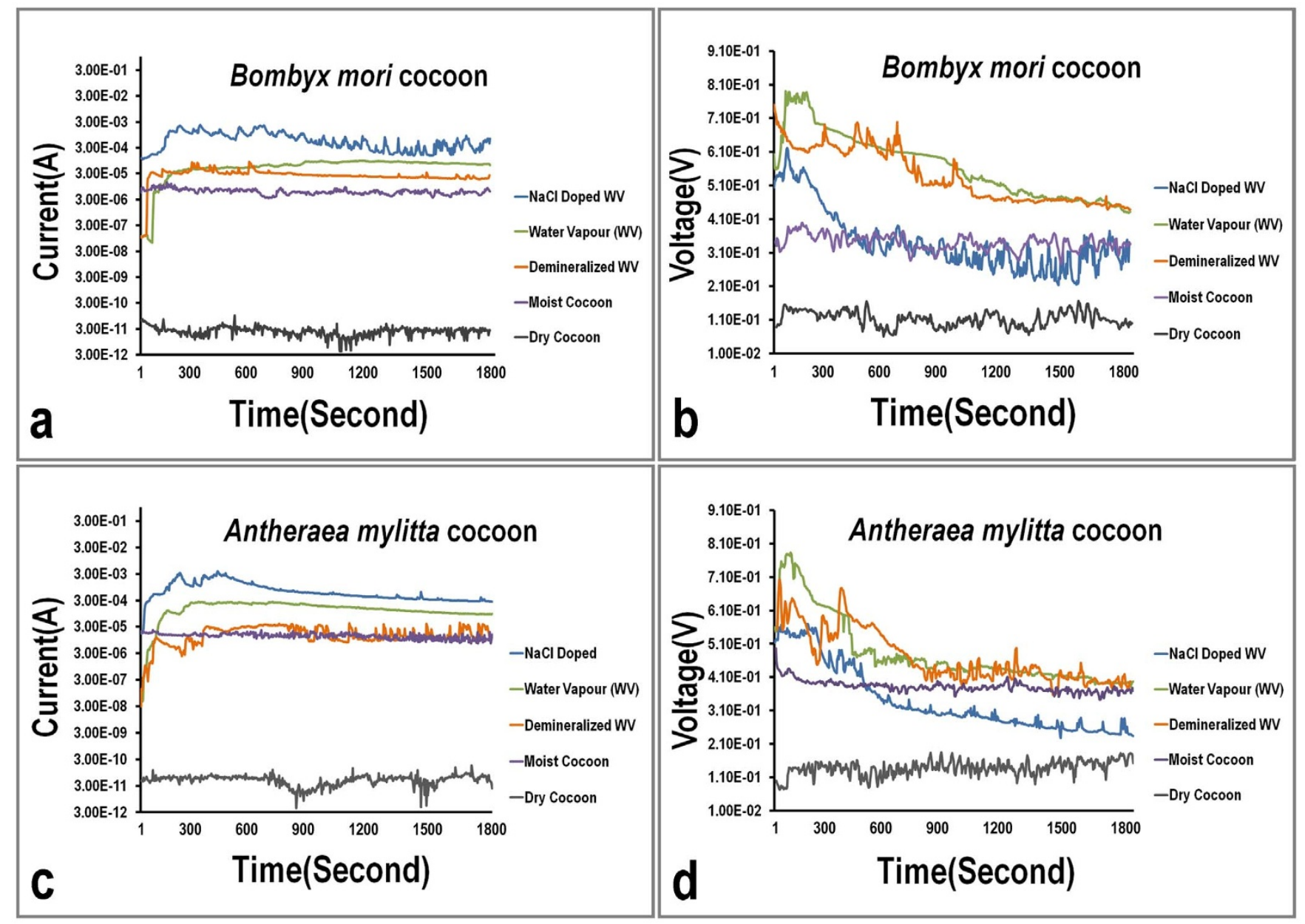

Figure 5 Studying electrical properties of SCM using standard device. (a) Average current recording obtained from Bombyx mori SCM under five different conditions (dry cocoon, moist cocoon, cocoon exposed to water vapor, cocoon sample treated with EDTA so as to di-mineralize the sample and exposed to water vapor, cocoon doped with $\mathrm{NaCl}$ and exposed to water vapor). The current traces shown for each condition is the average of 6 trials using six different SCM. In dry state current is negligible, as the SCM is moistened current value increased drastically. Exposing the cocoon to water vapor further increased the current value. There is a lowering of current value in demineralized cocoon. Maximum current values could be seen in the $\mathrm{NaCl}$ doped SCM exposed to water vapor. (b) Average voltage recording obtained from Bombyx mori SCM under five different conditions (as mentioned above). The voltage traces shown for each condition is the average of 6 trials using six different SCM. Voltage reading is negligible in dry state as compared to moist SCM. (c) Average current recording obtained from Antheraea mylitta SCM under five different conditions as mentioned previously. A similar current pattern as described for Bombyx mori is observed in Antheraea mylitta SCM. (d) Same pattern of voltage reading could be seen in Antheraea mylitta.

found it to be $1151 \pm 66 \mu \mathrm{S}$ for Antheraea mylitta and $325 \pm 70$ for Bombyx mori, $\mathrm{n}=6$ (mean \pm standard error; $\mathrm{n}=$ number of cocoons tested), $626 \pm 25 \mathrm{ppm}$ and $152 \pm 15 \mathrm{ppm}$ for Antheraea mylitta and Bombyx mori respectively, $\mathrm{n}=6$ (Conductivity meter: Cyberscan Con 11; Eutech Instruments). Previous results from EDAX studies indicated the presence of $\mathrm{Na}$ and $\mathrm{Cl}$ elements in SCM (Figure 3 ). When we performed simple precipitation test, to verify the presence of simple salts in the water, which has passed through the SCM, we observed a white precipitation indicating silver chloride (AgCl) (Figure S4, Supplementary information). This could indicate the possibility of the presence of common salt like $\mathrm{NaCl}$ in native SCM. This is indirectly supported by our previous observation that the current flux increases in $\mathrm{NaCl}$ doped cocoons (Figure 5, table 2). We have further verified our claim in a model 'porous

Table 2 | A comparative study of the current and voltage generated by two different SCMs under 5 different conditions ( $N a C l$ doped cocoon exposed to water vapor, demineralized cocoon (-D cocoon) exposed to water vapor, native cocoon exposed to water vapor, moist cocoon, and dry cocoon). The values indicated here are average values obtained from 6 different cocoon samples $(n=6)$ of each type

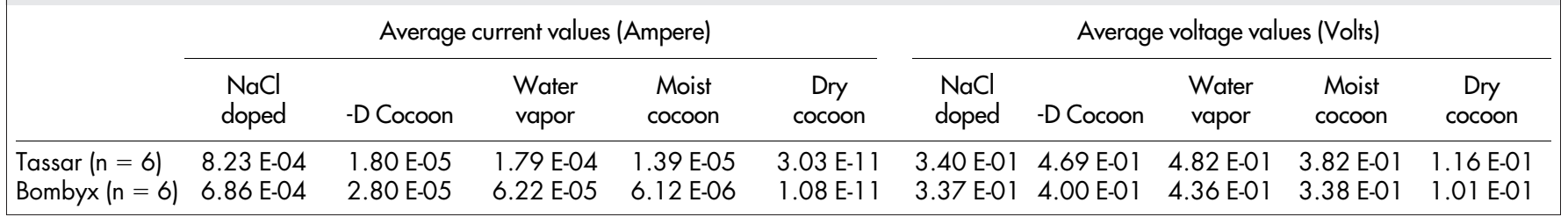




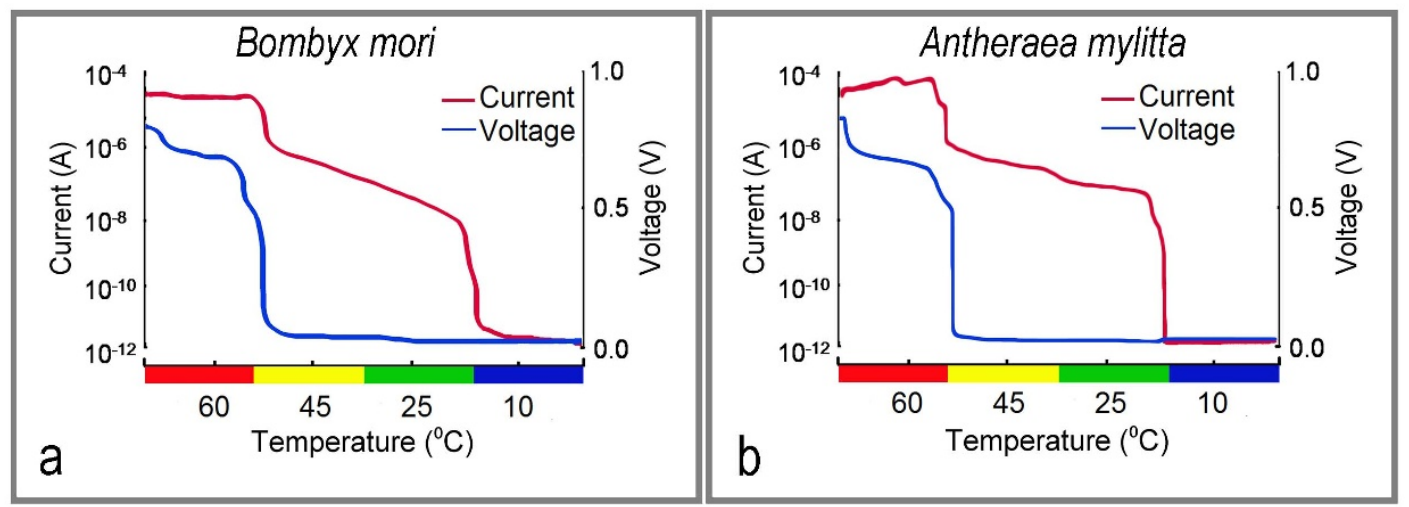

Figure 6 A snapshot of humidity and temperature dependent electrical properties of SCM. Current and voltage profiles are measured in the presence of RH $80 \%$. Decline in current values of both SCM are observed as temperature falls, whereas a sharp rise in voltage across the SCM was observed around $45^{\circ} \mathrm{C}$ while a constant trend in the temperature could be observed at the range of $25-45^{\circ} \mathrm{C}$. (a) Bombyx mori (b) Antheraea mylitta.

paper device', which has been discussed later. We assume that these salts dissociate into ions on interaction with water molecules, thus resulting in observed ionic current across SCM.

Nuclear magnetic resonance (NMR) of whole SCM to study the effects of hydration on the porous SCM and sodium mobility across SCM. Figure 8 showed the ${ }^{1} \mathrm{H},{ }^{13} \mathrm{C}$ and ${ }^{23} \mathrm{Na}$ cross polarization (CP) NMR spectra of dry and water vapor exposed Bombyx mori and Antheraea mylitta cocoon. Structural changes in the cocoon matrix due to water vapor could be reflected in the NMR spectrum. Bombyx mori is a widely studied system using solid state NMR spectroscopy. The detailed methodology of obtaining the spectra is described in the methods section ${ }^{57,58}$. ${ }^{1} \mathrm{H}$ NMR spectra of dry cocoons show three distinct peaks, one at $4.95 \mathrm{ppm}$ and another broad peak at $1.75 \mathrm{ppm}$ and $1.33 \mathrm{ppm}$. Broad peak at $4.95 \mathrm{ppm}$ is assigned as free water resonance and other peaks at 1.7 and $1.33 \mathrm{ppm}$ are assigned to organic part (silk fibroin). ${ }^{13} \mathrm{C} \mathrm{CP}$ spectra of Bombyx mori was assigned as reported earlier ${ }^{59}$. Water vapor exposure changed ${ }^{1} \mathrm{H}$ NMR spectra of cocoons; instead of a broad line, we get a sharp peak of water and well-resolved peak of silk fibroin methyl proton $\left(\mathrm{CH}_{3}\right)$. Sharp peaks were observed due to increase in motional averaging due to water vapors. Ala $C \beta{ }^{13} \mathrm{C}$ chemical shift is quite useful for probing the backbone conformations due to high sensitivity in proteins ${ }^{60}$. In ${ }^{13} \mathrm{C} \mathrm{CP}$ spectra of Bombyx mori cocoons, we observed three distinct chemical shifts of Ala $\mathrm{C} \beta$ at 17.5, 20.8 and $22.6 \mathrm{ppm}$. Similar kind of ${ }^{13} \mathrm{C}$ shifts was observed in earlier studies ${ }^{59}$. In the water vapor exposed SCM, we found that Ala $\mathrm{C} \beta$ chemical shift changes significantly to $17.9,21.0$ and $22.9 \mathrm{ppm}$.
Similar changes were observed in case of carbonyl peaks, Ala $\mathrm{C}=\mathrm{O}$, Ser $\mathrm{C}=\mathrm{O}$, and $\mathrm{Gly} \mathrm{C}=\mathrm{O}$ upfield shift of 0.1 and $0.2 \mathrm{ppm}$. Changes in carbonyl chemical shift could be possible due to change in interaction within chains ${ }^{61}$. Similar results were observed in Antheraea mylitta (Figure 8). In summary, ${ }^{1} \mathrm{H}$ and ${ }^{13} \mathrm{C}$ NMR spectrum of intact cocoon silk fiber shows an increase in dynamics of side chain as well as back bone, due to hydrations. This is reflected due to observed decrease in line width. This observation is consistent with earlier hydration studies on similar silk fiber by NMR relaxation studies ${ }^{62,63}$. Similar results were observed in Antheraea mylitta (Figure 8). In summary, ${ }^{1} \mathrm{H}$ and ${ }^{13} \mathrm{C}$ NMR spectrum of intact cocoon silk fiber shows an increase in dynamics of side chain as well as back bone, due to hydrations. This is reflected due to observed decrease in line width. However, till date there is no report on the ${ }^{23} \mathrm{Na}$ NMR studies of silk fiber. Since $\mathrm{Na}^{+}$can be possible source of charge carrier, it will show characteristic features in the ${ }^{23} \mathrm{Na}$ NMR spectrum of silk fibers. This motivated us to carry out ${ }^{23} \mathrm{Na}$ NMR to check whether there was any change in the mobility of $\mathrm{Na}$ ions which are present in the Cocoon matrix, due to vapor which contributes to electrical conduction. Figure 8 shows ${ }^{23} \mathrm{Na}$ spectra of dry Bombyx mori and Antheraea mylitta along with its spectrum in wet state. In the case of Bombyx mori cocoon, the spectrum in dry state is broad and shows less sensitivity. This observation is due to less concentration of ${ }^{23} \mathrm{Na}$ in the silk matrix of Bombyx mori and absence of any motion of ${ }^{23} \mathrm{Na}$ in dry state. It should be noted that concentration of ${ }^{23} \mathrm{Na}$ in Antheraea mylitta is more than Bombyx mori (since signal was detected in less transients; $18 \mathrm{k}$ compared to $80 \mathrm{k})$. But when vapour was passed through Bombyx mori and Antheraea mylitta, we observed that
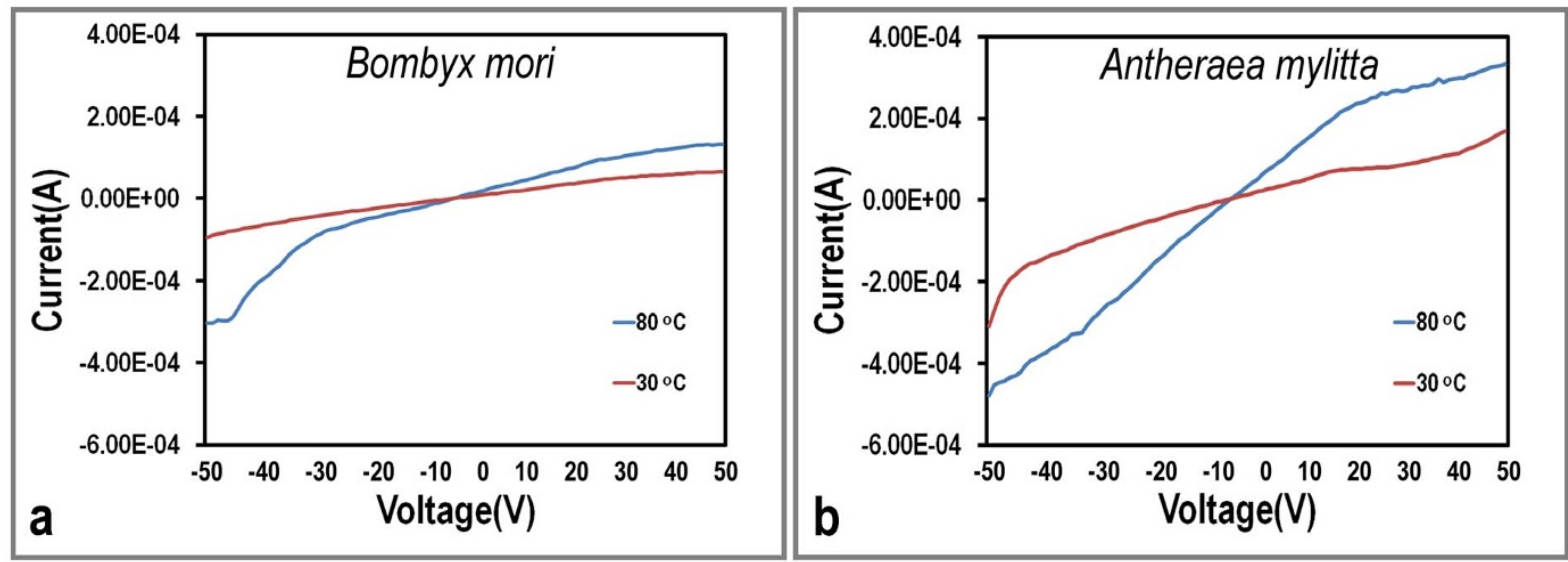

Figure $7 \mid$ Current-voltage (I-V) characteristics of SCM at $30^{\circ} \mathrm{C}$ and $80^{\circ} \mathrm{C}$. An inverse relationship between resistivity and temperature could be observed. (a) Bombyx mori (b) Antheraea mylitta. 


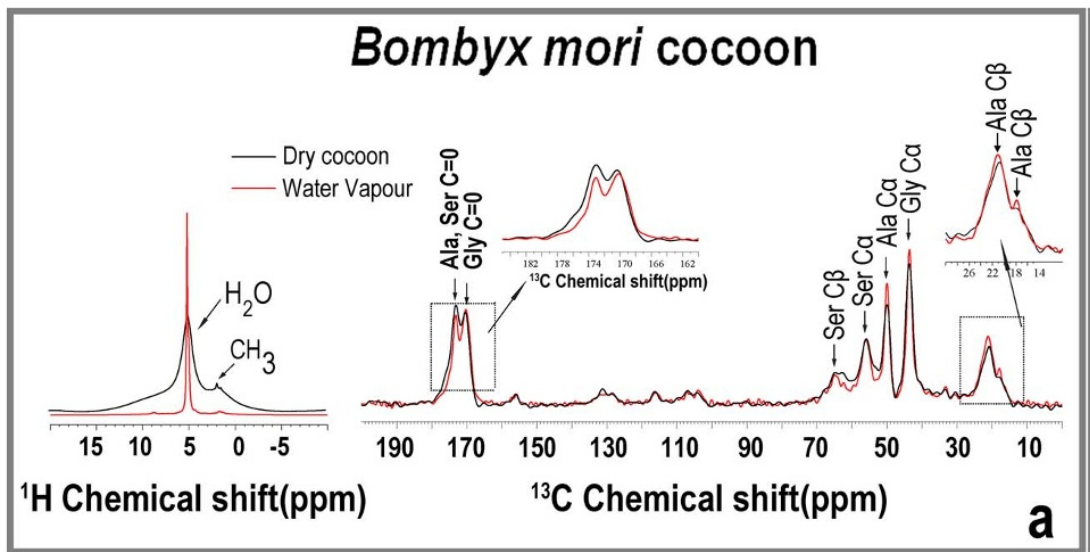

\section{Bombyx mori cocoon}
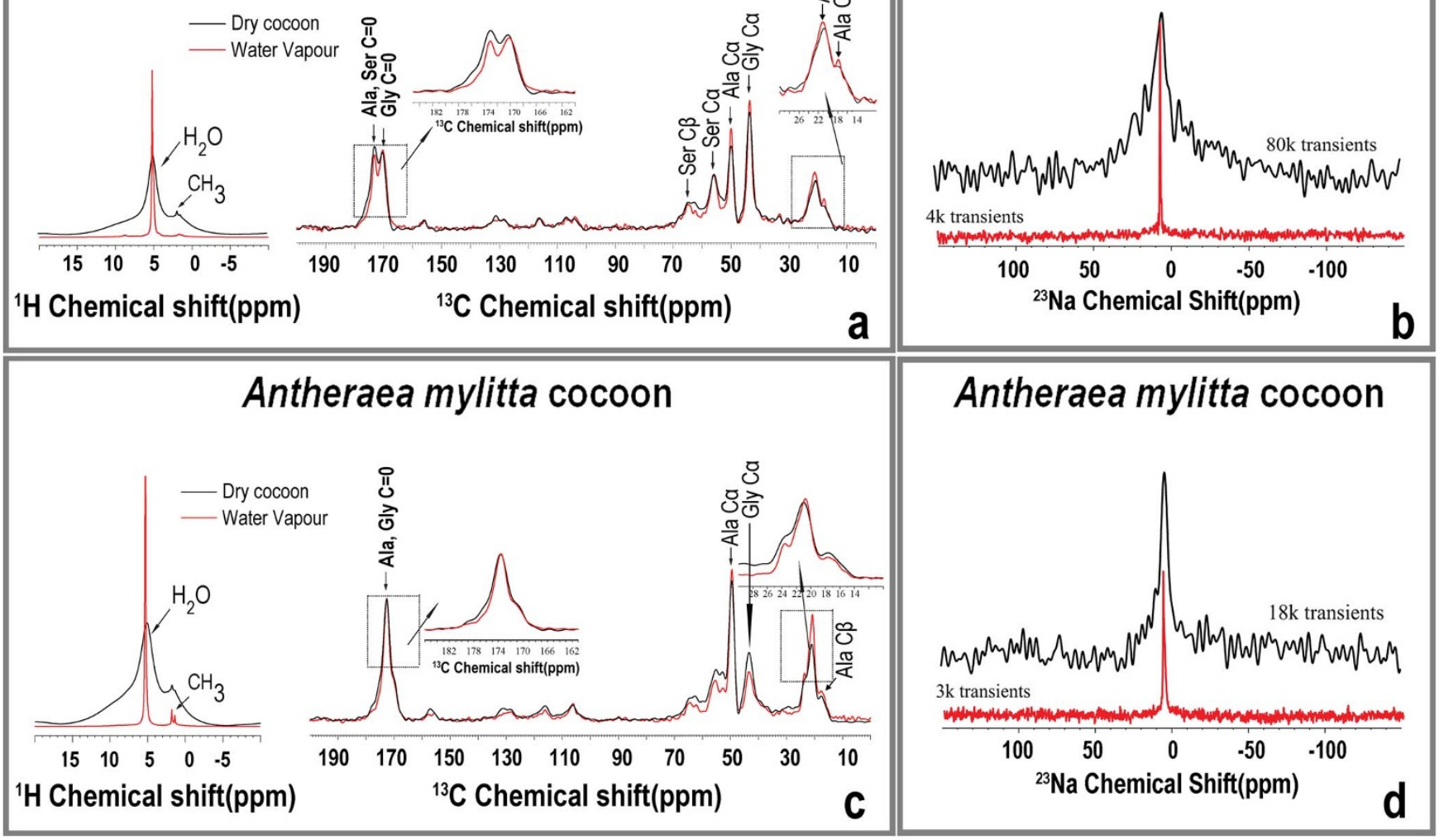

Figure 8 Proton $\left({ }^{1} \mathrm{H}\right)$, carbon-13 $\left({ }^{13} \mathrm{C}\right)$ and ${ }^{23} \mathrm{Na}$ Nuclear magnetic resonance (NMR) studies of dry cocoon sample and water vapor exposed cocoon sample. (a) and (c) for Bombyx mori cocoon. (b) and (d) for Antheraea mylitta cocoon.

${ }^{23} \mathrm{Na}$ spectra become quite sharp. This can only be result of increase in motion of ${ }^{23} \mathrm{Na}$ ions. Thus we can conclude that in the presence of water vapor, there is an increase in the motion of $\mathrm{Na}^{+}$ions present in the cocoon matrix, which is possibly reflected in the electrical measurement of water vapor exposed silk cocoons.

EDAX analysis of SCM before and after an "electrical experiment". In order to obtain more information about the distribution of ions before and after electrical experiments, we performed the EDAX analysis of the same sample. In the supplementary information (Figure S6), we have given the EDAX measurement before and after an "electrical experiment". But using EDAX we could not decipher any real change in ion distribution across the silk cocoon membrane before and after the electrical measurements.

Electrochemical impedance spectroscopy (EIS) to measure the charge mobility across SCM. We experimentally verified the charge mobility across SCM in dry, humidified and water vapor exposed conditions using EIS. A marked change in the charge transfer resistance was observed across SCM upon comparing dry, humidified and upon water vapor exposure conditions. Complex power analysis graph of the SCM under dry, humidified and upon water vapor exposure conditions showed the marked difference in relaxation time constant (Figure S7, These experiments were performed using both Bombyx and Antheraea cocoons but data is presented only for the Antheraea in the supplementary information). Relaxation time constant is a representative of the diffusion kinetics and provides an estimation of the degree of mobility of charges under different conditions ${ }^{64,65}$. Lesser the time constant, higher is the mobility. Time constant $(\tau)$ of the silk cocoon is calculated from complex power analysis of the impedance data, which is obtained under dry, wet and water vapor exposed conditions. The dry samples do not revel any information due to very high resistance. Time constant between two successive moves of protein chains in SCM in humidified and water vapor exposed cocoon showed active and reactive power response with frequency. The reactive power dominates at lower frequency and active power at higher frequency. Reactive power supports the movement of the polymer chain. The meeting point where the reactive and active power responses meet on frequency axis gives the time constant. This point implicates the time to which the visco-elastic forces are balanced and the system is in rest. Time constant $\sim 0.15 \mathrm{~ms}$ for SCM is obtained upon exposure to water vapor whereas in humidified conditions it was found nearly 4 times higher $(5.5 \mathrm{~ms})$. These results support the fact that when SCM is exposed to water vapor, this enhanced the chain mobility and thus facilitating ionic movement and the final result could be visualized as resultant charge transfer.

Extracting usable power from silk cocoon to operate low power electronic systems. Our observations showed that by modulating the surrounding moisture and the temperature, we could generate electricity from the SCM. This motivated us to explore the possibility of extracting 'usable power' from silk cocoon for operating low power electronic systems. As a 'proof of concept', here we have developed few simple, crude, 'functional cocoon devices' by integrating silk cocoon with light emitting diode (LED). The LED is powered by extracting the electrical energy from cocoon. In the device cocoon has been treated as a circuit component. For developing the device, each cocoon was prepared by removing the dead pupae, then planting the inner electrode by wrapping aluminum foil on the inner surface of the cocoon, while the 
counter electrode was planted on the outer surface using copper wires (Figure 9). In the case of Antheraea cocoons, colloidal silver paste is used to fix the electrodes on the inner and outer surfaces of cocoon. For the Bombyx, no colloidal paste was used. Colloidal paste was needed for Antheraea cocoons, so as to hold the electrodes on the surface. The electrodes could be attached on Bombyx surface much more easily without any requirement of colloidal paste. In our standard device, we did not use any colloidal silver for both Antheraea and Bombyx. The cocoons were then resealed carefully using 'Felx Kwik' instant adhesive (Pidilite Industries Limited, India). We use only a small drop of adhesive.

The first device was constructed by connecting three Bombyx cocoons and a LED in series (Figure $10 \mathrm{a}, \mathrm{b}$ ). Then outer surface of this cocoon circuit was exposed to water vapors. The power generated in the cocoon circuit could glow a red LED (minimum voltage and current requirement for red LED is $1.6 \mathrm{~V}$ and $18 \mu \mathrm{A}$ respectively). Thus showing that it is feasible to extract usable power from silk cocoon to operate low power electronic system. We observed similar results with devices made from the cocoons of Bombyx mori (Movie S1, Supplementary information) and Antheraea mylitta cocoons. Except in the Antheraea mylitta based device, we have used seven cocoons and connected them in combinations of series and parallel circuits (Figure S8, Movie S2, Supplementary information).

The asymmetric mobility of water molecules across $\mathrm{SCM}^{29}$, prompted us to design a device, where the water vapors was exposed to the inner surface of the cocoon. This device is developed only using only Antheraea mylitta cocoons. In this device, four Antheraea cocoons were connected in a series circuit along with a LED (Figure $10 \mathrm{c}, \mathrm{d}$ ). Cocoons were prepared as described previously in Figure 9. For exposing the inner surface of the cocoon with uniform water vapor, these four cocoons were connected with hallow plastic tubing. We observed a stable lighting of the red and blue LED. The water vapors got trapped inside the cocoons and diffuse in a uniform rate across the membrane, which results in steady-state current and voltage, which could further be verified by noticing a continuous glow of red and blue LED (Movies S3, S4, Supplementary information). The minimum voltage and current requirements for a blue LED is $2.4 \mathrm{~V}$ and $11 \mu \mathrm{A}$ respectively.

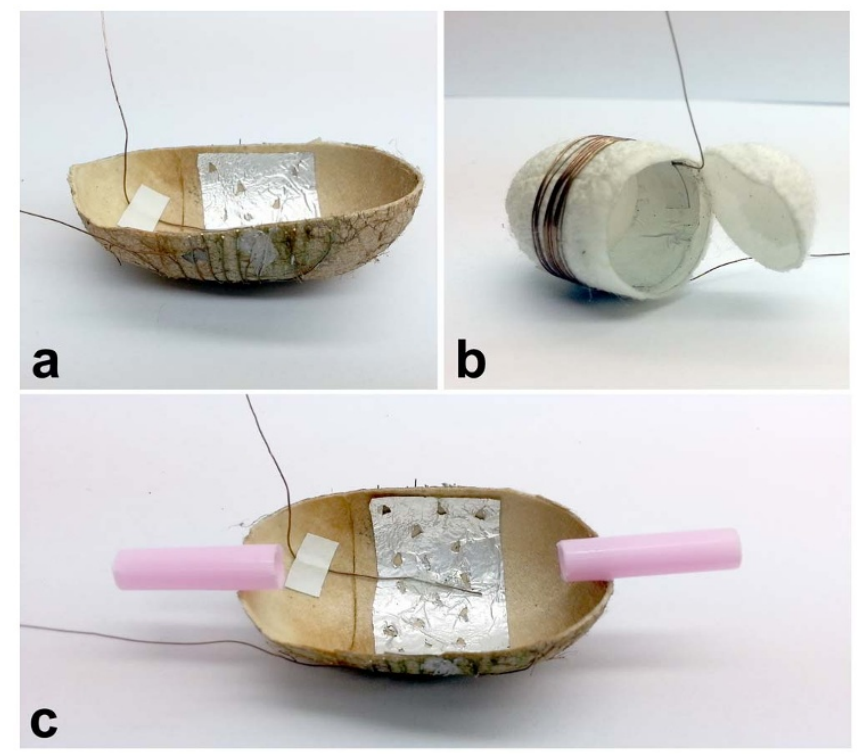

Figure 9 - Construction of a crude device from silk cocoon to extract electricity to power a light emitting diode (LED) (a) Transverse section of the Antheraea mylitta cocoon (b) Cross section of the Bombyx mori (c) Positioning of the plastic pipe for uniform distribution of water vapor. In all of the devices inner electrode was aluminum foil and the outer electrode was copper wire.
The structural feature of SCM resembles to a system, which can behave as a 'solid polymer dielectric electrolytic capacitor', where porous protein membrane can be considered as a dielectric and humidity activated charge carriers as electrolyte. This proposed concept persuaded us to examine the effect of applied voltage across the SCM. To investigate this, a single cocoon was used, with electrodes connected as described previously (Figure 9). Then the outer surface of this cocoon was sprinkled for few times with deionized water from different angles so that it covers the whole surface area of the SCM uniformly. Then it was charged for 2 minutes by applying a $12 \mathrm{~V} \mathrm{DC}$ source. The objective was to allow the charge moieties to migrate to either sides of the membrane, according to their respective polarity and generate sufficient potential difference. Then, we disconnected the source and connect the device to a red LED and it glowed for 2-3 minutes, utilizing the discharging current of the cocoon (Figure $10 \mathrm{e}$, f). These observations confirmed the charge storage capability of SCM. We observed similar results with devices made from the cocoon of Bombyx mori (0.36 mm thickness) (Movie S5, Supplementary information) as well as Antheraea mylitta (0.40 mm thickness) (Movie S6, Supplementary information). This device could be termed as a 'protein based capacitor'.

Developing a uniform, standard device using SCM to extract power. The fabrication of crude, raw devices inspired us to fabricate a standard smaller device, which could be used to investigate the system for developing green energy technologies. The standard device was made using both Bombyx (Movie S7, Supplementary information) and Antheraea (Movie S8, Supplementary information) SCM. The picture and the dimensions are shown in figure 11 and construction is described in methods section. After assembling and connecting it in series, the device was kept inside a falcon tube, which was supplied with water vapor. Instantaneous lighting up of the red LED was observed in the device developed from Antheraea. The device made out of Bombyx took slightly more time to activate the LED, as compared to Antheraea mylitta.

Performance testing of the device. Performance of the device was tested as the function of time (Figure 4). During performance test, we observed that electricity generation was decreasing with time. We took the reading for 3.5 hours. The average values for current and voltage after 3.5 hours of operation are comparable in both types of SCM (Figure 12). We observed a drop in the values of current and voltage after 200 minutes. But once the device was removed and retested after one hour, it again continued to give constant reading for another 200 minutes. The reason behind such behavior might be that SCM is getting super saturated following continuous exposure to water vapor. So once the water vapor source is removed, and the device is allowed to equilibrate with the surrounding, the device again starts to function at a constant value. Hence if the device is kept under a very controlled steam flow, we could continuously extract electricity from it, till it attains a state of super-saturation.

Proposed schematic representation of charge mobility across SCM. SCM is a porous fibrous protein matrix. It is doped with trace amounts of $\mathrm{Na}, \mathrm{Cl}, \mathrm{K}, \mathrm{S}, \mathrm{Ca}, \mathrm{Mg}, \mathrm{Cu}, \mathrm{Zn}$. When the surface of SCM is exposed to varying temperature, in the presence of humidity, we observed that it generates electricity. Such matrix allows the movement of water molecules and ions, along with dynamic changes in the structure by side chain mobility as observed in NMR and EIS studies. Based on our results, we are proposing a working model, which attempts to explain the origin of electrical current in SCM (Figure 13).

Porous paper device. Our proposed model (Figure 9) inspired us to test the system using a 'standard porous matrix'. We selected standard 'whatman filter paper'. We prepare a similar device as 


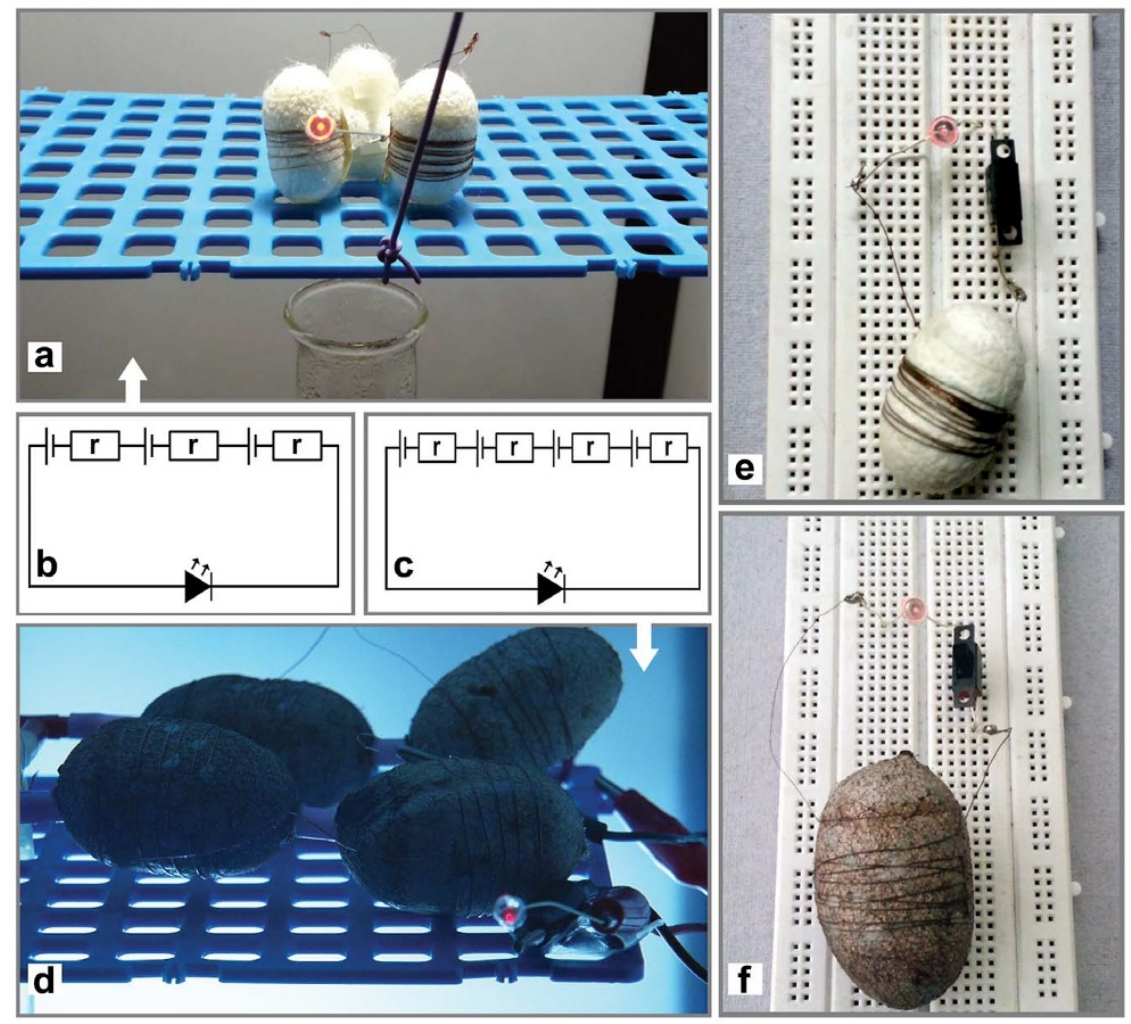

Figure 10 | Silk cocoon based 'crude device' (a) Device made from Bombyx mori silk cocoons. The device is behaving as an energy converter. When exposed to water vapor it generates sufficient power to operate a LED. (b) Circuit diagram for Bombyx mori silk cocoon device shown in (a). It is showing that each cocoon unit is represented as a battery with an internal resistance ' $r$ '. (c) Circuit diagram for Antheraea mylitta silk cocoon device. (d) Device made from Antheraea mylitta silk cocoons. In this device, water vapor is supplied inside the silk cocoon, which ensures uniform distribution of water vapor all over the inner surface and generates sufficient power to operate a LED. (e), (f) Silk cocoon as "protein based capacitor". Bombyx mori (White) and Antheraea mylitta (Brown) silk cocoons, when moistened and charged with 12 V DC source showed energy storing capability. (Movie S1-6, Supplementary information).

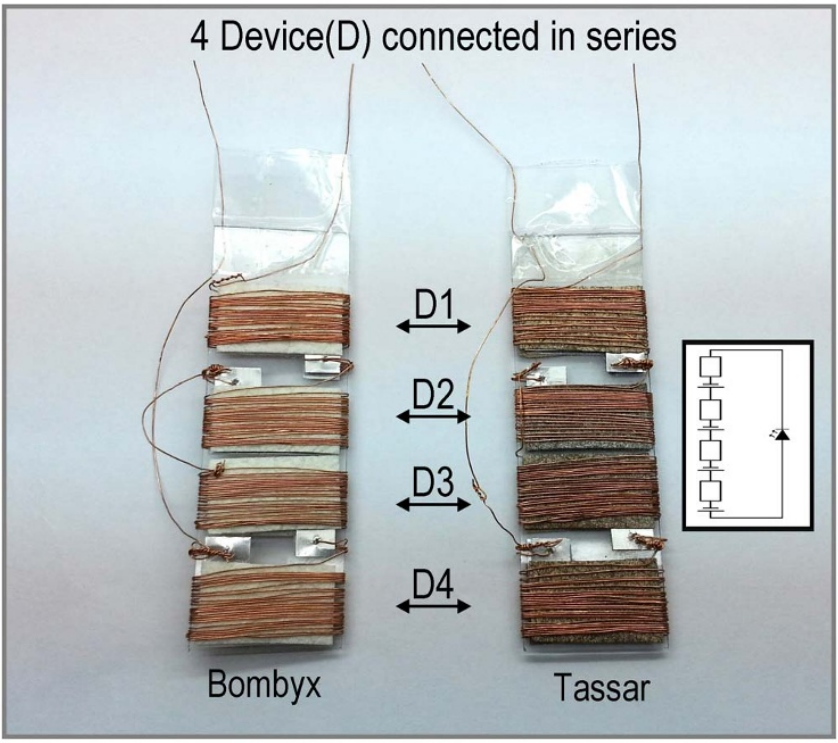

Figure $11 \mid$ Developing a uniform, standard device using SCM to extract power. D1, D2, D3, D4 represents the individual device units. Each device unit have the same dimensions as given in figure 5 . These were connected in series, which lit up a Red LED (Movie S7, S8, Supplementary information). Inset showing the circuit diagram of how these 4 device units have been connected. described earlier for SCM. In this device, instead of SCM we used 'whatman filter paper' (Figure 14). We recorded the current and voltage in dry, moist, water vapor exposed and $\mathrm{NaCl}$ doped + water vapor exposed devices. We observed that a filter paper acts in the same way as the SCM does (Figure 14, Movie S9, Movie S10, Supplementary information).

\section{Discussion}

We initiated our investigation with two questions and a working hypothesis (Refer to introduction section). We systematically studied the macro and micro-structural details of the SCM (Figure 1, 2), performed a mineral analysis for common ion forming elements (Figure 3), quantified the porosity of the two SCM (Table 1) and quantified the electrical parameters of both the cocoon types (Table 2, Figure 4-7). We observe the presence of $\mathrm{Na}, \mathrm{K}, \mathrm{Cl}, \mathrm{S}, \mathrm{Mg}$ in both the membranes. Electrical studies indicated that, when dry, SCM behaves like an insulator. On absorbing moisture, it generates electrical current, which is further modulated by temperature. One of the possible explanation of this observation could be the following: When the cocoon is humidified, the water molecules percolates into the fibrous matrix of the SCM and interacts with the minerals like $\mathrm{Na}$, $\mathrm{K}, \mathrm{Cl}$ and may results in the formation of ionic charge carriers. NMR findings, partly supports our assumption (Figure 8). NMR data revealed clearly that silk fibers are mainly beta sheet structures with a dense hydrogen-bonding network. The presence of water molecules in the fibrous protein matrix could facilitate the motion of charge species like sodium along the matrix and could be modulated by temperature. NMR spectra revealed increase in the dynamics of the protein side chains and protein back-bone, due to hydration. 


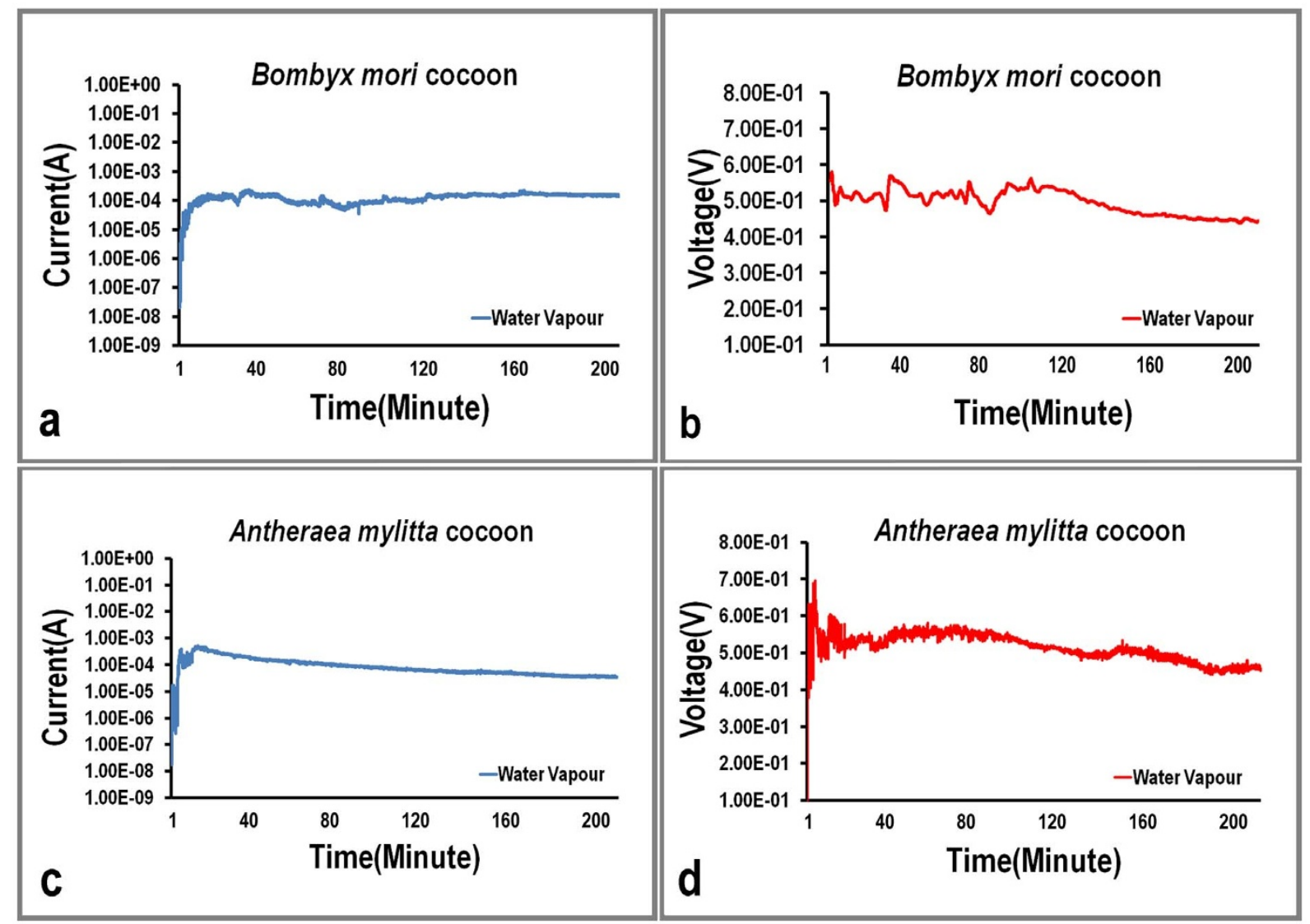

Figure $12 \mid$ Performance testing of the device (a) Current values of Bombyx mori is plotted in respect to time. As time increases the current values are slowly decreasing. (b) Voltage values of Bombyx mori also decreases with time. (c), (d) Similar current and voltage curve is seen in case of Antheraea mylitta.

Further motion of the charge species (Sodium) is observed in NMR, thus supporting our working hypothesis of generation of current in the SCM due to ionic charge carriers. Further EIS results showed enhanced charge mobility in hydrated cocoons exposed to water vapor (Figure S6).

Further we observed that there is a lowering of the current values in demineralized cocoons exposed to water vapor and increase in current value by doping the cocoon with $\mathrm{NaCl}$ (Figure 5). Table 1 and 2 highlights another interesting aspect regarding the porosity and current density of the Bombyx and Antheraea SCM. The Bombyx SCM has a higher porosity as compared to Antheraea. So we assume, high porosity will promote faster current flux and we will see more current density in Bombyx. Yet the Antheraea SCM exhibits higher current density. This may be partly due to the higher elemental

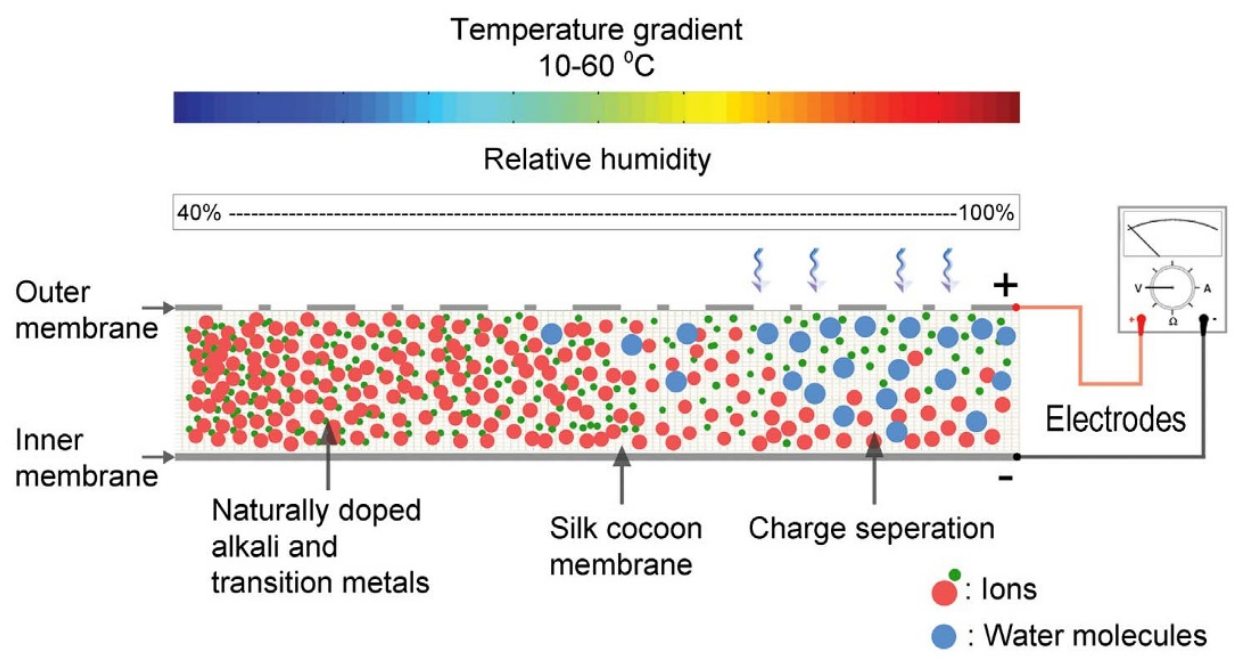

Figure 13 The proposed model showing the mechanism of current flow across SCM. In the absence of RH, there is hardly any current flow across SCM. As surrounding RH and temperature is increased, water molecules get trapped in the pores of SCM, and interact with the protein backbone and with certain naturally occurring ion forming elements, which possibly causes charge mobilization, resulting in the observed current. 


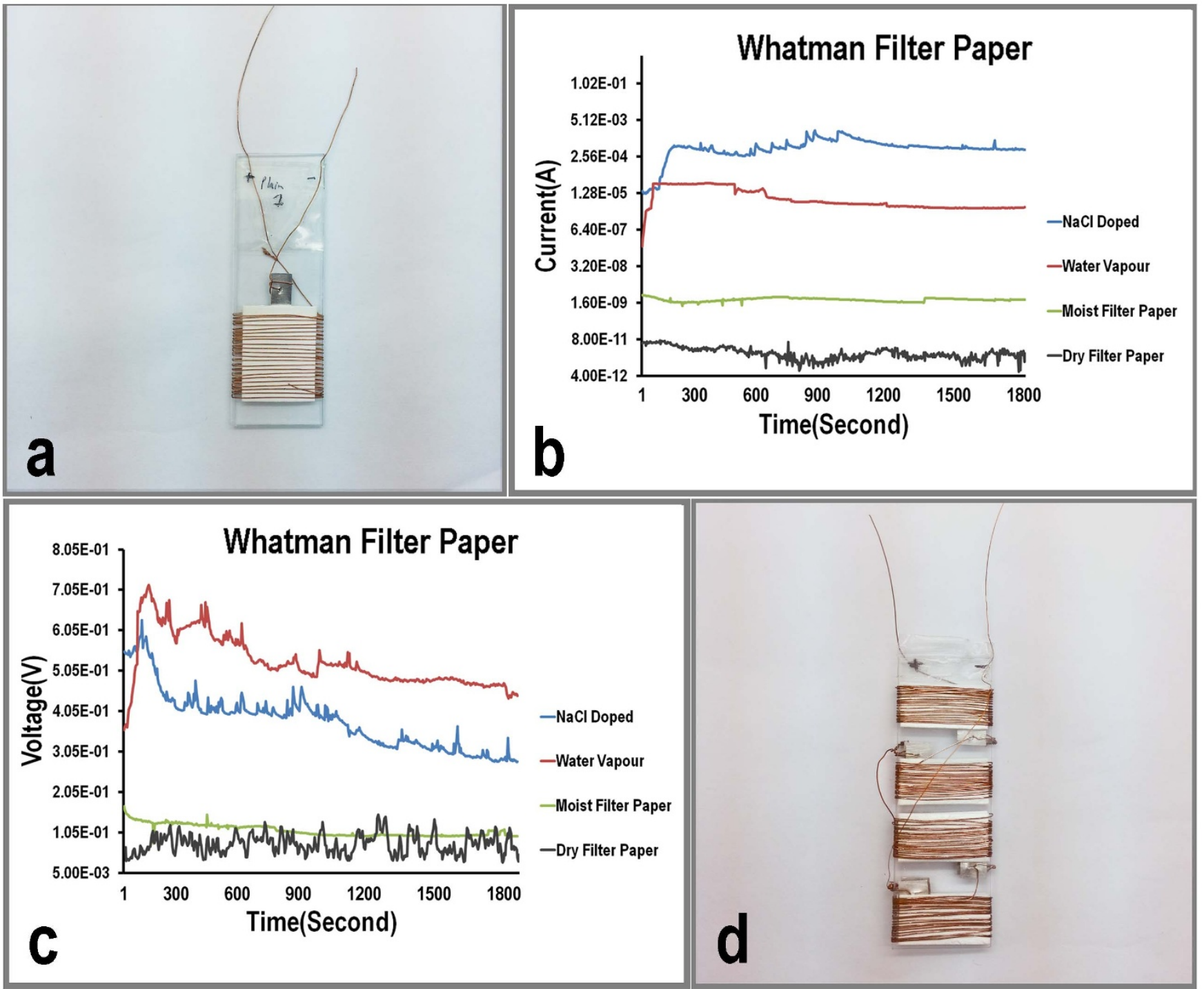

Figure $14 \mid$ Porous paper device (a) In this device SCM was replaced by a standard whatman filter paper. Thickness of the filter paper was 0.45 mm. (b) Negligible current were recorded in dry state. The current values increased sharply when the device was exposed to a steam of water vapor. When doped with $\mathrm{NaCl}$ and exposed to water vapor, the current values were maximum. (c) Maximum voltage values were recorded when the device is exposed to water vapor and the voltage values are negligible in dry state. (d) Functional device was prepared to power Red LED (Movie S9, S10, Supplementary information).

content in Antheraea. Further understanding in future could be gained by engineering these structures in a controlled environment, where the porosity and doping could be controlled.

Our assumption of ionic current is further supported by 'porous paper device' experiment (Figure 14). In this experiment, we replaced the porous cocoon membrane with a standard 'Whatman filter paper', and doped it with $\mathrm{NaCl}$. On exposing this filter paper membrane to a stream of water vapor, it generated sufficient electricity, which could power a light emitting diode. Based on these findings, we proposed a working model highlighting 'how the porous membrane of SCM could generate electricity' (Figure 13).

Our next question was 'How we could harness sufficient electricity from silk cocoon for some useful work?' Using the simple principles of electrochemistry, we developed certain simple devices, which demonstrated the potential that these could be used for low power electronics applications (Figure 9-12, Supplementary information Video S1-S10).

We initiated our investigation with a simple working hypothesis. Our result partly supports the hypothesis that ionic motion across hydrated SCM leading to the generation of electric current and the current flux is modulated by temperature'. Our hypothesis did not take into account the possible interaction between water and protein molecules (sericin and fibroin proteins of native silk fiber). But in hindsight, we wondered whether the protein-water interaction is playing any role in charge transfer across SCM. On careful observation of our data, one could clearly see that we are able to harness maximum electrical energy from hydrated SCM at a temperature around $50^{\circ} \mathrm{C}-60^{\circ} \mathrm{C}$ and above (Figure 6). We observe a characteristic current and voltage spike at around $50^{\circ} \mathrm{C}-60^{\circ} \mathrm{C}$. This simple observation warrants the need to analyze our results in terms of proteinwater interaction at a temperature around $60^{\circ} \mathrm{C}$ and above. Hence we asked the following questions to dissect the problem in terms of protein-water interaction:

1. What happens to the hydrated silk protein at temperature around $50^{\circ} \mathrm{C}-60^{\circ} \mathrm{C}$ and above, since we are observing maximum changes in electrical properties around this temperature?

2. Does this protein-water interaction at the above mentioned temperature range plays any role in charge transfer? 
In order to answer the first question, we need to understand the thermal properties of the silk protein biomaterial under dry and hydrated conditions. Silk protein has a very compact crystal structure, which is resistant to interaction with water molecules. But the amorphous region (disordered region) of the silk protein is accessible to water molecules. The interaction of the water molecules with the amorphous regions of the silk protein disrupt the amide-amide hydrogen bonds, improves the mobility of the protein chains and make these regions more plastic. This results in the lowering of 'glass transition' temperature (Tg) of the silk protein. Differential scanning calorimetry data has revealed that there is a gradual reduction of the Tg with increasing moisture content in amorphous fibroin films of Antheraea pernyi, Bombyx mori and dragaline spider silk ${ }^{63,66-74}$. In the case of Bombyx mori, a reconstituted amorphous silk fibroin film containing $5 \%$ moisture showed a Tg at around $60^{\circ} \mathrm{C}$, whereas a dry film showed a $\mathrm{Tg}$ at $178^{\circ} \mathrm{C}^{70}$. The reconstituted amorphous fibroin film developed using Antheraea pernyi revealed a similar Tg value at around $60^{\circ} \mathrm{C}^{73}$. Interestingly, a more recent study on native Bombyx mori silk cocoon using dynamic mechanical thermal analysis (DMTA) has revealed certain very interesting informations, which are different from the results obtained previously from reconstituted silk fibroin films of Bombyx mori ${ }^{75}$. In native silk, the loss tangent curve showed an increased molecular movement and enegy dissipation at around $60^{\circ} \mathrm{C}$. Authors of this study claimed that loss tangent at $60^{\circ} \mathrm{C}$ is not really $\mathrm{Tg}$, instead it is highlighting an increased mobility of water molecules in native silk matrix ${ }^{75}$. Earlier a similar result was obtained in soybean protein film ${ }^{76}$. Further such an increase in mobility of water molecules across the native silk protein matrix may lead to the rearrangements of the hydrogen bonding network across the matrix. Summarizing the answer to the first question, at around $60^{\circ} \mathrm{C}$, there is an increased mobility of water molecules and rearrangement of the hydrogen bond within SCM. This essentially leads us to the second question. Could such an rearrangement of hydrogen bonding across SCM due to increase mobility of water, results in some form of charge transfer?

Our second question demanded us to revisit two five decades old findings ${ }^{77,78}$ and a more recent quantum dynamical simulation study on water mediated proton hopping in proteins ${ }^{79}$. The key concept of these studies is the following: Hydrated proteins could exhibit enhanced electronic and electrochemical activity due to watermediated proton hopping taking place due to peptide and peptenol flip flopping. The activation energy for peptide-peptenol state change is $40 \mathrm{~kJ} / \mathrm{mole}$. Recent computational studies have shown that possibility of peptide-peptenol activation is fairly low under nonhydrated conditions, since in non-hydrated protein, a high activation energy $(76 \mathrm{~kJ} / \mathrm{mole})$ is needed for the $\mathrm{NH}$ bond fission ${ }^{79-83}$. Such water mediated proton hopping is enhanced with the increase mobility of the water molecules surrounding the protein and will continue till the water is lost from the protein surface and the denatured state is reached. Further the peptide-peptinol flip-flop event could be transmitted along the backbone of the protein, without need for any kind of physical motion of the protons along the protein chain. Thus such an event of water mediated proton hopping could play a significant role in charge transfer ${ }^{79}$.

In the light of these proton hopping studies in proteins, if we now look at our experimental results carefully, and arrange them logically, we see the possibility of the phenomenon of charge transfer by water mediated proton hopping across SCM at around $60^{\circ} \mathrm{C}$. We are enumerating our observations and others in a logical manner.

1. The SCM is inherently asymmetric in terms of water movement across its matrix and thereby could maintain a water gradient ${ }^{29}$. Such a gradient could be helpful in any form of charge transfer ${ }^{79}$.

2. SCM could generate current only when it is hydrated. Thus at the molecular level protein-water interaction is an essential criterion for current generation. In other words, the electrical properties of the protein improves in the presence of water, a very basic assumption for water mediated proton hopping ${ }^{79}$.

3. Current generated by hydrated SCM is thermo-electric in nature, since it changes with temperature. At the molecular level, rising temperature increases the thermal motion of the water molecules surrounding the protein, as well as leads to motion of the protein side chains. These molecular motions could results in some form of charge generation by rearranging the hydrogen bond network. This essentially points to the possibility of water mediated proton hopping.

4. At around $60^{\circ} \mathrm{C}$, we observe a spike in current and voltage. In other words, we observe enhanced electrical activity in hydrated SCM around $60^{\circ} \mathrm{C}$. Interestingly at around the same temperature (i.e $60^{\circ} \mathrm{C}$ ), there is an increased mobility of water molecules (as observed by other group while studying the thermal properties of native silk and soybean protein film ${ }^{75,76}$ ) and this may results in rearrangement of the hydrogen bonds within SCM. Thus hinting at the possibility of a water mediated proton hopping by peptide-peptenol flip-flopping at around $60^{\circ} \mathrm{C}$.

5. NMR studies indicated enhanced protein chain movement, water and sodium mobility in hydrated SCM when exposed to water vapor. EIS studies revealed an enhance charge mobility in hydrated SCM exposed to water vapor.

6. Lastly we observe a comparable current and voltage spike in Bombyx SCM at $60^{\circ} \mathrm{C}$ with respect to Antheraea, though Bombyx has a very low mineral content.

This brings us to an interesting conjecture: A. Is the observed spike in current and voltage around $60^{\circ} \mathrm{C}$, is purely ionic (as hypothesized by us earlier). If so how we could explain for the comparable current and voltage spike in Antheraea and Bombyx SCM at $60^{\circ} \mathrm{C}$ ? or B. The observed current and voltage spike is partly due to 'water mediated proton hopping by virtue of peptide-peptenol flip-flop in the SCM' thus leading to charge transfer. Since in our system, the water vapor is continuously hydrating the SCM protein matrix, and maintaining it at a temperature around $60^{\circ} \mathrm{C}$, so we possibly see a prolonged current flux. So at this point, we are concluding that we are possibly observing both ionic and water mediated proton-hopping charge transfer in SCM. Further, this lead us to think that, such a water mediated proton-hopping phenomenon could be more pronounced in proteins which forms extensive hydrogen bonding networks, and a dynamic change in the thermal properties of the proteins could be seen at around $60^{\circ} \mathrm{C}$ in other proteins too ${ }^{76}$ and if such proteins are used to develop energy harvesting devices, then we could be able to harness significant clean energy in a sustainable way. Further this thermo-electrical phenomenon should be explored in other 4000 poorly studied silk producing insects to understand how the electrical properties of silk proteins have evolved in nature and what are their broad significance in terms of evolution.

The future challenge will be to quantify the contribution of the individual current components and thus differentiating the ionic and proton hopping components. This will require further manipulation of the electrochemical conditions and use of synthetic silk material whereby we can control the geometry, micro-nano structural features of the synthetic membrane and regulate the concentrations of naturally occurring elements which are found in varying concentrations in native silk.

In the case of porous paper, we are possibly observing pure ionic current. We are currently exploring a hybrid approach, where we can modify paper with more functional molecules (like proteins) so as to create a functionally much robust protein-cellulose paper matrix. Such an approach could surely open up a new vista of sustainable technologies, specially considering the fact that paper is more economical and we can produce proteins at a competitive cost in bioreactors. In future, we will be exploring the possibility of using paper and other proteins to develop similar energy harvesting devices. 
One of the most pertinent questions is, where this kind of technology could find an immediate application. Waste heat management could be one of the possible sectors. In recent time, it has become a critical issue and has gained significant attention, with "no waste" philosophy. The main areas, which contribute most in the heat dissipation, are power generation sector, thermal power plants, nuclear power plants, iron ore/steel industry, paper pulp industry and other industrial processes. These have serious impacts on environment and the ecosystem. Building a system, which could utilize the humidified waste heat for energy harvesting, thus reducing the environmental hazards would be an ideal solution. Based on our findings, an inspiration can be drawn from these insect-engineered materials. If such structures are emulated by exploiting modern micro and nanofabrication tools, these could be an answer for mankind's ever increasing demand for waste heat management, green and sustainable energy.

In conclusion, we wish to reiterate the fact that, we initiated our studies with the background information of few long forgotten papers of Jacob S Ishay ${ }^{24,46,53}$ and came to a possible conclusion about our results, whose scientific roots goes back to the seminal publication of Theodor Grotthuss in 1806 'Theory of water conductivity's4 and the subsequent trail of studies during last one century on water mediated proton hopping in proteins ${ }^{77-79}$.

\section{Methods}

Procuring silk cocoons. The shinning bright, white colored, fine Bombyx mori are procured from the state of Karnataka in India (Figure S2). The off-brown colored Antheraea mylitta are procured from the state of Orissa and Chhattisgarh in India. The specimens of both these cocoon are shown in figure 1 . The procured cocoons were dried under the sun to make sure the pupae inside is dead then cocoons were cleaned with a electric blower and kept in a dust free, dry wooden cabinet for further use. The Bombyx are smaller in size as compared to the Antheraea.

Scanning electron microscopy. SUPRA 40 VP field emission scanning electron microscope (Carl Zeiss NTS GmbH, Oberkochen (Germany) is used to obtain the scanning electron micrograph images of the silk cocoons membrane as shown in figure 2. Energy-dispersive X-ray spectroscopy was done using oxford instruments

Porosity calculation. Dimensions of all the samples were initially measured using micrometer. The pore volume of native and demineralized samples was calculated by fluid uptake method using water and water plus acetic acid $(1: 1)^{56}$. Both native and demineralized samples were initially dried to constant mass by placing them in hot air oven, following that weight of each sample was measured. The samples were then immersed in water or water + acetic acid. In both the techniques, the samples are kept at a negative pressure for one hour for complete saturation of samples and removal of any trapped air in void spaces. Weight of individual saturated samples was then again measured. Porosity of the samples was then calculated as follows:

$$
\text { Porosity }=\frac{\text { Msaturated sample }- \text { Mdried sample }}{\text { Msaturated sample }}
$$

'Demineralized' cocoon samples were prepared by the method described in one of the earlier work, where ethylenediaminetetraacetic acid (EDTA) was used for demineralization process $^{32}$.

SCM preparation for electrical measurement. Clean dried SCM was cut in small rectangular $(2.5 \mathrm{~cm}$ by $2 \mathrm{~cm}$ ) pieces. We prepared 3 kinds of samples (Native SCM, demineralized SCM and $\mathrm{NaCl}$ doped SCM). 'Demineralized' samples are prepared by the method described in one of the earlier work ${ }^{32}$

Electrical measurement set up. Electrical measurements are performed using Keithley's 51/2-digit Model 6517B electrometer/high resistance meter (Keithley Instruments, Inc. 28775, Aurora Road, Cleveland, Ohio, 44139, USA; http://www. keithley.com/company). This offers significantly high accuracy and sensitivity to measure very low-level currents. It has ability to measures resistances up to $1016 \Omega$ and a current ranging from $1 \mathrm{fA}-20 \mathrm{~mA}$. It has $<20 \mu \mathrm{V}$ burden voltage on lowest current ranges and having $200 \mathrm{~T} \Omega$ input impedance. It has $<3 \mathrm{fA}$ bias current and up to $425 \mathrm{rdgs} / \mathrm{s}$. The instrument has a noise level of $0.75 \mathrm{fA}$ p-p noise and equipped with a built-in $\pm 1 \mathrm{kV}$ voltage source. The electrical measurements are carried out inside a faraday cage. The faraday cage is placed on a vibration isolation table. These precautions are taken so as to reduce the surrounding noises.

Standard Device preparation for evaluating the electrical parameters of SCM. The high purity copper wires 32 AWG and 32 Gauge Aluminum sheets are used as electrodes. The dimensions of the electrodes used are given in the figure 4 . Then prepared SCM were sandwiched between the two electrodes using glass slide as the base. We have treated the SCM in a similar way as a simple electrochemical cell. Similar to simple electrochemical cell, we used two different metal electrodes with different electronegativity values. Electronegativity of aluminum is 1.61 while that of copper is 1.90 using Pauling scale.

Conductivity and TDS measurements. Conductivity meter of the make Cyberscan Con 11; Eutech Instruments is used for measuring the conductivity and TDS. The cocoons are cut open and after removing the pupae, these are fixed on a stand as shown in figure S3-S5. Then these cocoons are filled with deionized water and as the water percolates through the membrane and start to come out from the other side, it is collected in a sterile beaker and the conductivity is measured. The precipitation test is performed using high purity $\mathrm{AgNO}_{3}$ solution (Figure S4).

Whole cocoon sample preparation for NMR studies. We performed NMR studies of whole cocoon samples. For all solid-state NMR (ssNMR) experiments, cocoon was cut in small rectangular sheet to fit inside a $3.2 \mathrm{~mm}$ rotor. NMR experiments was performed first in its native form i.e., dry form. Then the sample was exposed to water vapors for 5 minutes in rotor through stream of vapor for next experiments. The sample was packed tightly after exposure to avoid any water loss during the course of NMR experiment.

NMR spectroscopy. All ssNMR spectra were recorded on $600 \mathrm{MHz}$ solid-state NMR spectrometer (Avance III, Bruker Biospin, Switzerland) operating at $600.154 \mathrm{MHz}$ for ${ }^{1} \mathrm{H}$, and $150.154 \mathrm{MHz}$ for ${ }^{13} \mathrm{C}$ frequencies with Bruker's 3.2 DVT probe. The magic angle spinning (MAS) speed was controlled by Bruker's MAS pneumatic unit within accuracy of $\pm 2 \mathrm{~Hz}$. All ssNMR experiments were recorded at MAS speed of $10 \mathrm{kHz}$. The ${ }^{1} \mathrm{H} \pi / 2$ pulse for one pulse ${ }^{1} \mathrm{H}$ NMR experiment was $2.5 \mu \mathrm{s}$. It was recorded with $2 \mathrm{k}$ data point, acquisition time of $10.2 \mathrm{~ms}$ for each sample ${ }^{13} \mathrm{C}$ cross polarization (CP) spectra were recorded with ramp cross polarization sequence, $1.0 \mathrm{~ms}$ contact time and SPINAL-64 decoupling (100 kHz ${ }^{1} \mathrm{H}$ r.f. field). We recorded total $10 \mathrm{k}$ transients with acquisition time of $7.75 \mathrm{~ms}$ and recycle delay was 3 seconds. The ${ }^{23} \mathrm{Na}$ $\pi / 2$ pulse for one pulse ${ }^{1} \mathrm{H}$ NMR experiment was $6.2 \mu \mathrm{s}$. It was recorded with different transients for wet cocoon ( $4 \mathrm{k}$ and $3 \mathrm{k}$ ) and dry cocoon $(18 \mathrm{k}$ and $80 \mathrm{k})$. The acquisition time for each ${ }^{23} \mathrm{Na}$ experiments was $18.2 \mathrm{~ms}$ for every sample.

Preparing cocoons for making 'crude cocoon devices'. The cocoons are cut open as described above. Then the aluminum electrode is implanted as shown in figure $9 a, b$. The copper wire electrode is implanted on the outer surface of the cocoon. The connection of plastic-pipes to supply water vapor inside the cocoon is shown in the cross sectional view of the cocoon in figures $9 \mathrm{c}$.

Construction of the standard, uniform, functional cocoon device. We cut out SCM with a dimension of was $1 \mathrm{~cm}$ by $2.5 \mathrm{~cm}$. Then SCM was sandwiched between two electrodes aluminum 32 gauge $(0.8 \mathrm{~cm}$ by $2.3 \mathrm{~cm})$ and Copper 32 AWG (1.1 meter) respectively. This was treated as single unit. Then it was connected in series as shown in figure 11. Positive (Copper end) and negative (Aluminum end) terminals of the device were connected to the red LED.

Porous paper device preparation. Standard Whatman filter paper (Cat No: 1001 125, GE Healthcare UK Limited, Amersham Place, Little Chalfont, Buckinghamshire, HP7 9 NA, UK) with thickness $0.18 \mathrm{~mm}$, pore size $11 \mu \mathrm{m}$ and dimension of $2.5 \mathrm{~cm}$ by $2 \mathrm{~cm}$ was taken. In order to match the thickness of cocoon, we put three layers of filter papers to make the device. Samples were prepared in similar manner as done for SCM. The device developed using filter paper followed the same dimensions of the electrodes as described for the SCM device (Figure 14).

1. Trouvelot, L. The American silk worm. Am. Nat. 1, 30-38 (1867).

2. Silkworms and moths. Sci. Am. 49, 39-41, doi:10.1038/ scientificamerican07211883-39 (1883).

3. Packard, A. S. A Text-book of Entomology: Including the Anatomy, Physiology, Embryology and Metamorphoses of Insects, for Use in Agricultural and Technical Schools and Colleges as Well as by the Working Entomologist. (The Macmillan company, New York, 1903).

4. Vollrath, F. Spider webs and silks. Sci. Am. 266, 70-76 (1992).

5. Vollrath, F. \& Selden, P. The Role of Behavior in the Evolution of Spiders, Silks, and Webs. Annu. Rev. Ecol. Evol. Syst. 38, 819-846, doi:doi:10.1146/ annurev.ecolsys.37.091305.110221 (2007).

6. Omenetto, F. \& Kaplan, D. From silk cocoon to medical miracle. Sci. Am. $\mathbf{3 0 3}$ 76-77 (2010).

7. Leal-Egaña, A. \& Scheibel, T. Silk-based materials for biomedical applications. Biotechnol. Appl. Biochem. 55, 155-167 (2010).

8. Shao, Z. \& Vollrath, F. Materials: Surprising strength of silkworm silk. Nature 418, 741-741 (2002).

9. Chen, F., Porter, D. \& Vollrath, F. Silkworm cocoons inspire models for random fiber and particulate composites. Phys. Rev. E 82, 041911 (2010).

10. Chen, F., Porter, D. \& Vollrath, F. Structure and physical properties of silkworm cocoons. J.R. Soc. Interface 9, 2299-2308 (2012).

11. Hartland-Rowe, R. The biology of the wild silkmoth Gonometa rufobrunnea Aurivillius (Lasiocampidae) in northeastern Botswana, with some comments on its potential as a source of wild silk. Botswana Notes and Records 24, 123-133 (1992). 
12. Guilford, T. Predator psychology and the evolution of prey coloration. Natural enemies: the population biology of predators, parasites and diseases. (Blackwell Scientific Publishers, 1992).

13. Gaston, K. J., Chown, S. \& Styles, C. Changing size and changing enemies: the case of the mopane worm. Acta. Oecol. 18, 21-26 (1997).

14. Akai, H. Anti-bacterial function of natural silk materials. Int. J. Wild Silkmoth \& Silk 3, 79-81 (1997).

15. Veldtman, R., McGeoch, M. \& Scholtz, C. Variability in cocoon size in southern African wild silk moths: implications for sustainable harvesting. Afr. Entomol. 10, 127-136 (2002).

16. Veldtman, R. The ecology of southern African wild silk moths (Gonometa species, Lepidoptera: Lasiocampidae): consequences for their sustainable use. $\mathrm{PhD}$ Thesis University of Pretoria, Pretoria (2005).

17. Zhao, H.-P., Feng, X.-Q., Yu, S.-W., Cui, W.-Z. \& Zou, F.-Z. Mechanical properties of silkworm cocoons. Polymer 46, 9192-9201 (2005).

18. Veldtman, R., McGeoch, M. A. \& Scholtz, C. H. Can life-history and defence traits predict the population dynamics and natural enemy responses of insect herbivores? Ecol. Entomol. 32, 662-673 (2007).

19. Veldtman, R., McGeoch, M. \& Scholtz, C. Fine-scale abundance and distribution of wild silk moth pupae. Bull. Entomol. Res. 97, 15-27 (2007).

20. Roy, M. et al. Carbondioxide gating in silk cocoon. Biointerphases 7, 1-11 (2012).

21. Blossman-Myer, B. \& Burggren, W. W. The silk cocoon of the silkworm, Bombyx mori: Macro structure and its influence on transmural diffusion of oxygen and water vapor. Comp. Biochem. Physiol., Part A Mol. Integr. Physiol. 155, 259-263 (2010).

22. Kusurkar, T. S. et al. Fluorescent silk cocoon creating fluorescent diatom using a "Water glass-fluorophore ferry". Sci. Rep. 3:3290, doi: 10.1038/srep03290 (2013).

23. Kaur, J. et al. Photo-protection by Silk Cocoons. Biomacromolecules DOI: 10.1021/bm401023h (2013).

24. Ishay, J. S. \& Barenholz-Paniry, V. Thermoelectric effect in hornet (Vespa orientalis) silk and thermoregulation in a hornet's nest. J. Insect. Physiol. 41, 753-759 (1995).

25. Kirshboim, S. \& Ishay, J. S. Silk produced by hornets: thermophotovoltaic properties-a review. Comp. Biochem. Physiol., Part A Mol. Integr. Physiol. 127, $1-20$ (2000).

26. Danks, H. V. The roles of insect cocoons in cold conditions. Eur. J. Entomol. 101,433-438 (2004).

27. Zhang, J., Rajkhowa, R., Li, J., Liu, X. \& Wang, X. Silkworm Cocoon as Natural Material and Structure for Thermal Insulation. Mater Design 49, 842-849 (2013).

28. Daimon, T. et al. The silkworm Green b locus encodes a quercetin 5-Oglucosyltransferase that produces green cocoons with UV-shielding properties. Proc. Natl. Acad. Sci. U.S.A. 107, 11471-11476 (2010).

29. Horrocks, N. P., Vollrath, F. \& Dicko, C. The silkmoth cocoon as humidity trap and waterproof barrier. Comp Biochem Phys A 164, 645-652 (2013).

30. Roy, M. et al. Graphene oxide from silk cocoon: a novel magnetic fluorophore for multi-photon imaging. 3 Biotech 4, 67-75 (2013).

31. Kundu, S. et al. Nonmulberry silk biopolymers. Biopolymers 97, 455-467 (2012).

32. Gheysens, T., Collins, A., Raina, S., Vollrath, F. \& Knight, D. P. Demineralization enables reeling of wild silkmoth cocoons. Biomacromolecules 12, 2257-2266 (2011)

33. Zhou, L. et al. Copper in the silk formation process of Bombyx mori silkworm. FEBS letters 554, 337-341 (2003).

34. Zong, X.-H. et al. Effect of $\mathrm{pH}$ and copper (II) on the conformation transitions of silk fibroin based on EPR, NMR, and Raman spectroscopy. Biochemistry 43, 11932-11941 (2004)

35. Wilaiwan, S., Chirapha, B., Yaowalak, S. \& Prasong, S. Screening of some elements in different silk cocoon varieties. J. Appl Sci 10, 575-579 (2010).

36. Vollrath, F. \& Knight, D. P. Liquid crystalline spinning of spider silk. Nature 410, 541-548 (2001).

37. Knight, D. P. \& Vollrath, F. Changes in element composition along the spinning duct in a Nephila spider. Naturwissenschaften 88, 179-182 (2001).

38. Dewitz, J. Zoologische Jahrbucher Abteilung fuer Allgemeine Zoologie und Physiologie der Tiere. 38, 365-404 (1921).

39. Ohnishi, E., Takahashi, S. Y., Sonobe, H. \& Hayashi, T. Crystals from Cocoons of Malacosoma neustria testacea. Science 160, 783-784 (1968).

40. Teigler, D. J. \& Arnott, H. J. Biological Sciences: X-ray Diffraction and Fine Structural Studies of Crystals in the Malpighian Tubules of Silkworms. Nature 235, 166-7 (1972).

41. Akai, H. Calcium crystals deposited in cocoons of wild silkmoths. Int. J. Wild Silkmoth \& Silk 6, 33-42 (2001).

42. Akai, H. \& Nagashima, T. Calcium crystals of cocoon shell from African Gonometa silkmoth (Lasiocampidae). Int. J. Wild Silkmoth \& Silk 8, 1-5 (2003).

43. Himmer, A. Die Temperaturverhältnisse bei den sozialen Hymenopteren. Biol. Rev. 7, 224-253 (1932)

44. Ishay, J., Bytinski-Salz, H. \& Shulov, A. Contributions to the bionomics of the Oriental hornet Vespa orientalis. Israel J. Em. 2, 45-106 (1967).

45. Kemper, H. \& Döhring, E. Die sozialen Faltenwespen Mitteleuropas. (Parey, Berlin, 1967).

46. Ishay, J. \& Ruttner, F. Thermoregulation im Hornissennest. Z Vergl Physiol 72, 423-434 (1971).
47. Spradbery, J. P. Wasps. An account of the biology and natural history of social and solitary wasps, with particular reference to those of the British Isles. (Sidgwick \& Jackson, London, 1973).

48. Edwards, R. Social wasps. Their biology and control. (Rentokil Ltd., Felcour, 1980). 49. Heinrich, B. Insect thermoregulation. (Wiley Interscience John Wiley \& Sons Inc. New York, 1981)

50. Brian, M. V. Social insects. Ecology and behavioural biology. (Chapman and Hall, New York, 1983)

51. Matsuura, M. \& Yamane, S. Biology of the vespine wasps. (Springer Verlag, Berlin, 1990)

52. Ishay, J. \& Ruttner, F. Die thermoregulation im hornisennest. Zeitschrift für vergleichende Physiologie 72, 423-434 (1971).

53. Ishay, J. \& Ben Shalom, A. Electric properties of Hornet silk: the influence of humidity and ether. Physiol Chem Phys Me 24, 323-328 (1992).

54. Sverdlov, A., Litinetsky, L., Pertsis, V. \& Ishay, J. Thermophotovoltaic (TPV) properties of hornet cuticle as dependent on relative humidity. Physiol Chem Phys Me 32, 57 (2000).

55. Ishay, J., Litinetsky, L., Linsky, D., Lusternik, V., Voronel, A. \& Pertsis, V. Hornet silk: thermophysical properties. Journal of Thermal Biology 27, 7-15 (2002).

56. Plieva, F. M. et al. Pore structure in supermacroporous polyacrylamide based cryogels. Soft Matter 1, 303-309 (2005).

57. Pines, A., Gibby, M. \& Waugh, J. Proton-Enhanced Nuclear Induction Spectroscopy. A Method for High Resolution NMR of Dilute Spins in Solids. J. Chem. Phys. 56, 1776-1777 (1972).

58. Saitô, H. et al. A high-resolution 13C-nmr study of collagen like polypeptides and collagen fibrils in solid state studied by the cross-polarization-magic anglespinning method. Manifestation of conformation-dependent 13C chemical shifts and application to conformational characterization. Biopolymers 23, 2279-2297 (1984).

59. Ando, S., Ando, I., Shoji, A. \& Ozaki, T. Intermolecular hydrogen-bonding effect on carbon-13 NMR chemical shifts of glycine residue carbonyl carbons of peptides in the solid state. J. Am. Chem. Soc. 110, 3380-3386 (1988).

60. Fung, B., Khitrin, A. \& Ermolaev, K. An improved broadband decoupling sequence for liquid crystals and solids. J. Magn. Reson. 142, 97-101 (2000)

61. Asakura, T. \& Yao, J. 13C CP/MAS NMR study on structural heterogeneity in Bombyx mori silk fiber and their generation by stretching. Protein Sci. 11, 2706-2713 (2002).

62. Geppi, M., Mollica, G., Borsacchi, S. \& Cappellozza, S. Proton Spin-Lattice Relaxation in Silkworm Cocoons: Physisorbed Water and Serine Side-Chain Motions. J.Phys. Chem B 114, 2586-2592 (2010).

63. Seydel, T. et al. Increased molecular mobility in humid silk fibers under tensile stress. Phys. Rev. E 83, 016104 (2011).

64. Garcia, B. B. et al. Effect of pore morphology on the electrochemical properties of electric double layer carbon cryogel supercapacitors. J. Appl Physics 104, 014305 (2008).

65. Berens, A. \& Hopfenberg, H. Diffusion and relaxation in glassy polymer powders: 2. Separation of diffusion and relaxation parameters. Polymer 19, 489-496 (1978).

66. Work, R. W. \& Morosoff, N. A physico-chemical study of the supercontraction of spider major ampullate silk fibers. Text. Res. J. 52, 349-356 (1982).

67. Parkhe, A. D., Seeley, S. K., Gardner, K., Thompson, L. \& Lewis, R. V. Structural studies of spider silk proteins in the fiber. J. Mol. Recognit. 10, 1-6 (1997).

68. Yang, Z. et al. Supercontraction and backbone dynamics in spider silk: $13 \mathrm{C}$ and 2H NMR studies. J. Am. Chem. Soc. 122, 9019-9025 (2000).

69. Holland, G. P., Lewis, R. V. \& Yarger, J. L. WISE NMR characterization of nanoscale heterogeneity and mobility in supercontracted Nephila clavipes spider dragline silk. J. Am. Chem. Soc. 126, 5867-5872 (2004).

70. Hu, X., Kaplan, D. \& Cebe, P. Effect of water on the thermal properties of silk fibroin. Thermochim. Acta 461, 137-144 (2007).

71. Agarwal, N., Hoagland, D. \& Farris, R. Effect of moisture absorption on the thermal properties of Bombyx mori silk fibroin films. J. Appl. Polym. Sci. 63, 401-410 (1997)

72. Plaza, G. R., Guinea, G. V., Pérez-Rigueiro, J. \& Elices, M. Thermo-hygromechanical behavior of spider dragline silk: Glassy and rubbery states. J. Polym. Sci., Part B: Polym. Phys. 44, 994-999 (2006).

73. Fu, C., Porter, D. \& Shao, Z. Moisture effects on Antheraea pernyi silk's mechanical property. Macromolecules 42, 7877-7880 (2009).

74. Doster, W. The dynamical transition of proteins, concepts and misconceptions. Eur. Biophys. J. 37, 591-602 (2008).

75. Guan, J., Porter, D. \& Vollrath, F. Thermally Induced Changes in Dynamic Mechanical Properties of Native Silks. Biomacromolecules 14, 930-937 (2013).

76. Tian, K., Porter, D., Yao, J., Shao, Z. \& Chen, X. Kinetics of thermally-induced conformational transitions in soybean protein films. Polymer S1(11), 2410-2416 (2010).

77. Oshida, I., Ooshika, Y. \& Miyasaka, R. Proton Transfer in Hydrogen Bond and Its Participation in $\pi$-Electron Systems. J. Phys. Soc. Jpn. 10, 849-859 (1955).

78. Schauenstein, E., Treiber, E., Berndt, W., Felbinger, W. \& Zima, H. UltraviolettAbsorptionsspektren von Seidenfibroin und Cellulose in Lithiumbromidlösung. Monatsh. 85, 120-139 (1954).

79. Porter, D. \& Vollrath, F. Water mediated proton hopping empowers proteins. Soft Matter 9, 643-646 (2013).

80. Ball, P. Water as an active constituent in cell biology. Chem. Rev. 108, 74-108 (2008) 
81. Porter, D. \& Vollrath, F. Water mobility, denaturation and the glass transition in proteins. Biochim. Biophys. Acta 1824, 785-791 (2012).

82. Pauling, $\mathrm{L}$. The nature of the chemical bond and the structure of molecules and crystals: an introduction to modern structural chemistry. Vol. 18 (Cornell University Press, 1960).

83. Porter, D. \& Vollrath, F. The role of kinetics of water and amide bonding in protein stability. Soft Matter 4, 328-336 (2008).

84. de Grotthuss, C. J. T. "Sur la décomposition de l'eau et des corps qu'elle tient en dissolution à l'aide de l'électricité galvanique”. Ann. Chim. 58, 54-73 (1806).

\section{Acknowledgments}

Funding from MD's start up grant at IIT K 'Exploring the novel semiconductor properties of pupal silk for applications in bioelectronics and biosensors' IITK/BSBE/20100206 (20102011). This work is BT's doctoral thesis. Special thanks to Prof. Raibatak Das (Department of Integrative Biology, University of Colorado, Denver) for his critical remarks on the manuscript. A sincere thanks to Prof. Satyaki Roy (Design Program) and the 'Media Center' of IITK for helping us with the video recordings and processing. We are exceptionally thankful to Mr. P Kagkachalam and Prof. G Anantharaman of Chemistry, IIT K for helping us with the DSC and thermo-gravimetric facility. MD specially thank Prof. Gurunath Ramanathan of Chemistry, IIT K for his stimulating discussion on proton hopping.

\section{Author contributions}

B.T. has developed the idea of harvesting energy from cocoon by developing the innovative bio-hybrid devices. Further he discovered that by exposing the silk cocoon to water vapor, sufficient energy could be generated, which is sufficient to operate low power electronic components. The discovery of the concept of treating silk cocoon membrane as a capacitor is purely his idea and he single-handedly demonstrated that cocoon membrane function as a capacitor device. He contributed significantly in the writing the manuscript. S.K.M. has studied the electrical properties of cocoon, discovered the humidity dependent current flow across Tassar silk cocoon membrane, made major contribution in writing the manuscript. R.K.R. and N.S. performed the NMR experiments and analyzed the results. A.K.T. and A.K conducted the porosity experiments and analyzed the results. C.M. and T.S.K. helped in the preliminary electrical recordings from the cocoon and developing the device. N.K.S. and K.B. helped us to understand the nature of the silk proteins, its ultrastructure and the SEM experiments. R.K.S. performed the EIS studies. S.B. helped in the thermal properties of silk S.K.S. and M.D. first conceived the idea of developing 'bio-inspired devices' from silk cocoon in the year 2010 and assisted in the experiments and guided in writing the manuscript. This is MD's start up grant at IIT K 'Exploring the novel semiconductor properties of pupal silk for applications in bioelectronics and biosensors' IITK/BSBE/ 20100206

\section{Additional information}

Supplementary information accompanies this paper at http://www.nature.com/ scientificreports

Competing financial interests: The authors declare no competing financial interests. How to cite this article: Tulachan, B. et al. Electricity from the Silk Cocoon Membrane. Sci. Rep. 4, 5434; DOI:10.1038/srep05434 (2014).

(i) $⿴$ This work is licensed under a Creative Commons Attribution-NonCommercialNoDerivs 4.0 International License. The images or other third party material in this article are included in the article's Creative Commons license, unless indicated otherwise in the credit line; if the material is not included under the Creative Commons license, users will need to obtain permission from the license holder in order to reproduce the material. To view a copy of this license, visit http:// creativecommons.org/licenses/by-nc-nd/4.0/ 